ORNL-2831

Controlled Thermonuclear Processes

\title{
CRITICAL CURRENT FOR BURNOUT IN \\ AN OGRA-TYPE DEVICE
}

Albert Simon

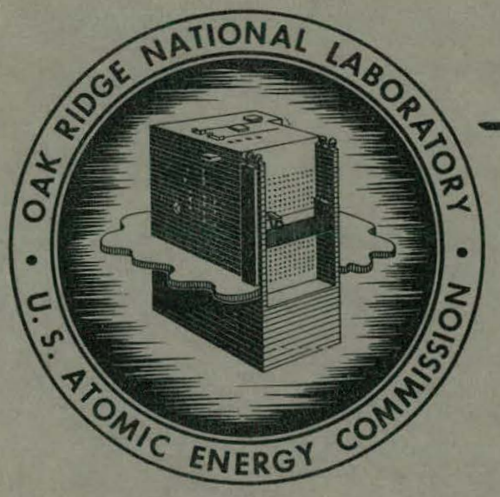

OAK RIDGE NATIONAL LABORATORY

operated by

UNION CARBIDE CORPORATION

for the

U.S. ATOMIC ENERGY COMMISSION 


\section{DISCLAIMER}

This report was prepared as an account of work sponsored by an agency of the United States Government. Neither the United States Government nor any agency Thereof, nor any of their employees, makes any warranty, express or implied, or assumes any legal liability or responsibility for the accuracy, completeness, or usefulness of any information, apparatus, product, or process disclosed, or represents that its use would not infringe privately owned rights. Reference herein to any specific commercial product, process, or service by trade name, trademark, manufacturer, or otherwise does not necessarily constitute or imply its endorsement, recommendation, or favoring by the United States Government or any agency thereof. The views and opinions of authors expressed herein do not necessarily state or reflect those of the United States Government or any agency thereof. 


\section{DISCLAIMER}

Portions of this document may be illegible in electronic image products. Images are produced from the best available original document. 


\section{Printed in USA. Price $\$ 1.50$. Available from the \\ Office of Technical Services \\ Department of Commerce \\ Washington 25, D.C.}

\section{LEGAL NOTICE}

This report was prepared as an account of Government sponsored work. Neither the United States, nor the Commission, nor any person acting on behalf of the Commission:

A. Makes any warranty or representation, expressed or implied, with respect to the accuracy, completeness, or usefulness of the information contained in this report, or that the use of any information, apparatus, method, or process disclosed in this report may not infringe privately owned rights; or

B. Assumes any liabilities with respect to the use of, or for damages resulting from the use of any information, apparatus, method, or process disclosed in this report.

As used in the above, "person acting on behalf of the Commission" includes any employee or contractor of the Commission, or employee of such contractor, to the extent that such employee or contractor of the Commission, or employee of such contractor prepares, disseminates, or provides access to, any information pursuant to his employment or contract with the Commission, or his employment with such contractor. 
Addendum to ORNL-2831

The units on the curves of Fig. 3 through Fig. 26 were inadverently omitted. The density $\mathrm{n}_{+}$is in $\mathrm{cm}^{-3}$ and the current $I$ is always in ma. 
ORNL-2831

Contract No. W-7405-eng-26

Neutron Physics Division

CRITICAL CURRENT FOR BURNOUT IN AN OGRA-TYPE DEVICE

Albert Simon

Date Issued

OCT 231959

OAK RIDGE NATIONAL LABORATORY

Oak Ridge, Tennessee

operated by

UNION CARBIDE CORPORATION

for the

U.S. ATOMIC ENERGY COMMISSION 


\section{ABSTRACT}

A complete algebraic analysis has been obtained for the variation of the steady state ion density $n_{+}$with injected current $I$ in an OGRA-type fusion device (i.e., a device based on trapping of ions by breakup of energetic molecular lons on collision with either, the background gas or trapped ions). The most general variation of $n_{+}$with $I$ is shown to be an s-curve with at most three roots of $n_{+}$for a given input $I$. A physical interpretation of these three roots is given. In addition algebraic expressions are obtained for the two currents at which the bends in the s-curve occur. It will be necessary to attain the larger current in order to build up a high density plasma when the density is being increased from below. On the other hand, once the high density has been achieved it may be maintained by steady injection of a current larger than the lower value. Parameters corresponding roughly to the specifications of OGRA are used to obtain some numerical results. In the final appendix, the previously. published formulas for burnout in DCX are extended to include effects of neutral backstreaming from the input beam and "ion-pumping." 
Page №.

Abstract

iii

I. Steady State Relation Between Ion Density

and Injected Current $\ldots \ldots \ldots \ldots \ldots \ldots \ldots \ldots \ldots \ldots$ I

II. The Injected Current as a Function of

the Ion Density ......................... 6

III. The Ion Density as a Function of the

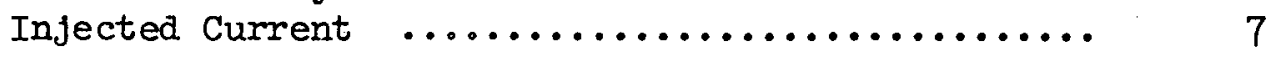

IV. Physical Tnterpretation of the Rooto .......... 11

V. The Upper Critical Current (UCC) ............. 12

VI. The Lower Critical Current (ICC) ............. 15

VII. Numerical Solutions for "OGRA" $\ldots \ldots \ldots \ldots \ldots \ldots \ldots \ldots . . \ldots$

VIII. Summary $\ldots \ldots \ldots \ldots \ldots \ldots \ldots \ldots \ldots \ldots \ldots \ldots \ldots \ldots \ldots \ldots$

App. A. The Path Length I Considered as a

Fixed Range ............................ 44

App. B. Extension of the DCX. Burnout Formula to

Include Ion Pumping

45 


\section{THIS PAGE}

\section{WAS INTENTIONALLY \\ LEFT BLANK}




\section{STEADY STATE RELATION BETWEEN ION DENSTTY AND INJECTED CURRENT}

In two previous publications, ${ }^{1-2}$ an expression was derived for the critical current at which formation of a plasma by high-energy injection will begin. This. previous expression was for a case in which the trapping mechanism (although not specified in detall) was localized and did not depend on either the neutral gas in the device, the trapped ion density or the dimensions of the system. A trapping mechanism of this sort is provided by the arc in $\mathrm{DCX}_{0}{ }^{3}$

The situation is quite different in a proposed fusion device such as OGRA. ${ }^{4}$. Here the injected molecular ions have a long mean-free-path I before they strike the injector snout and trapping occurs by virtue of the dissociation of the molecule on collision with either the background gas (cross section $\left.\sigma_{B}^{0}\right)$, the trapped ions $\left(\sigma_{B}^{+}\right)$, or other molecular ions in transit $\left(\sigma_{B}^{2+}\right)$. Nevertheless, one might suspect on physical grounds that a critical current also exists. In this case and indeed such an expression has been found. The result is somewhat more complex than in the case of DCX because of a feedback which is inherent in the gas-breakup scheme. The onset of neutral burnout results in a reduction of the neutral breakup centers as well as an increase of the ion breakup centers and hence has a back effect on the input trapped current.

A complete algebraic analysis of the steady state equations has been achieved in the case when one can neglect the contribution of the molecular ions to burnout or to breakup of other molecules as compared to the effect of the trapped ions and the neutral gas. (This is a highly valid approximation in almost all cases of interest.) The total mean free path $\lambda$ of the injected molecular.ions is then!

$$
\frac{1}{\lambda}=\frac{1}{L}+\hat{N}_{0} \sigma_{B}^{0}+n_{+B} \sigma^{+}
$$

1. A. Simon, The Phys. of Fluids, 1, 495. (1958).

2. A. Simon, The Phys. of Fluids, 2, 336 (1959).

3. C. F. Barnett et al., Proc. Second Geneva Conf. 31, 298 (1958).

4. I. V. Kurchatov, J. Nuc. Energy 8, 168 (.1958). 
where $\hat{N}_{0}$ is the average neutral density (atomic) external to the plasma region and $n_{+}$is the trapped energetic ion density. (It has been assumed that the slow ions resulting from ionization of the neutrals in the plasma region contribute equally to breakup as do the neutrals themselves. The sum of the slow ion and neutral densities in the plasma interior should remain equal to the external neutral density even after burnout.) The probability that a molecule will break up after a path length $x$ is then

$$
p(x)=e^{-x / \lambda} \frac{d x}{\lambda_{B}}
$$

where

$$
\frac{I}{\dot{\lambda}_{B}}=\hat{N}_{0} \sigma_{B}^{0}+n_{+} \sigma_{B}{ }^{+}
$$

The percentage trapping is found by integrating Eq. (2) over all space. The result is

$$
\% \text { B.U. }=\frac{\lambda}{\lambda_{B}}=\frac{\hat{N}_{0} \sigma_{B}^{o} L+n_{+} \sigma_{B}^{+} L}{1+\hat{I N}_{O}{ }^{O}{ }_{B}{ }^{O} L+n_{+} \sigma_{B}^{+} L}
$$

The steady state rate of trapping of energetic ions is obtained by multiplying Eq. (4) by I, where I is the injected (number) current of molecular ions. It is assumed that trapping bydissociation of the molecular ion will dominate over trapping by actual ionization.

The trapped ions will be lost from the plasma in two ways. Either they undergo a charge exchange coljision with a background gas atum or they scatte $1^{*}$ on each other and go out the mirrors. Since mirror loss will be negligible until well after burnout sets in; we ignore any contribution to mirror loss due to scattering of the ions against the neutral gas atoms. The average neutral density $\bar{n}$ in the plasma interior is simply related to the exterior neutral density $\hat{N}_{0}^{0}$. 


$$
\bar{n}_{0} \cong \frac{\hat{N}_{0}}{1+\frac{\ell}{\lambda}}
$$

$$
=\frac{\hat{\mathrm{N}}_{0}}{1+\frac{\bar{l} \mathrm{v}}{v_{0}} \mathrm{n}_{+} \sigma_{\mathrm{d}}^{+}}
$$

Here $\bar{l}$ is the mean chord length of the plasma volume and $\lambda$ is the mean-freepath for destruction of a gas atom (by either ionization or charge exchange) as it enters the plasma. Equation (6) expresses this mean free path in terms of the properties of the ions. The quantity $\sigma_{d}^{+}$represents the sum of the cross sections for ionization and charge exchange of an ion incident on a gas atom:

$$
\sigma_{\mathrm{d}}^{+}=\sigma_{i}+\sigma_{\mathrm{cx}}
$$

The background gas has been assumed to be of the same species as the injected molecular ion (i.e., deuterium or hydrogen in all cases of interest). Hence a single ionization or charge exchange suffices to make it impotent. The average velocity of the gas atom is denoted by $v_{0}$ and $v$ is the ion velocity. Throughout this paper we assume that energy degredation processes are unimportant and that the ions remain at their initial energy until they are lost.

The steady state loss rate of ions by charge exchange follows immediately from: Eq.. (6). It is:

$$
=\frac{\hat{\mathbb{N}}_{0} n_{+} \sigma_{c x} v V}{1+\frac{l_{v}}{v_{0}} n_{+} \sigma_{d}^{+}}
$$


where $\mathrm{V}$ is the plasma volume. Finally, the mirror loss rate is assumed to be given by the usual binary expression; 5

$$
=n_{+}^{2} \sigma_{c} v \mathrm{PV}
$$

where $\sigma_{c}$ is the "effective 90-deg. Coulomb scattering cross section". by cumulative small angle scattering and $\mathrm{P}$ is the probability of an ion being in the loss cone after such a scattering. Combining Eqs. (4), (8), and (9), we have the following steady state equation for the ion density:

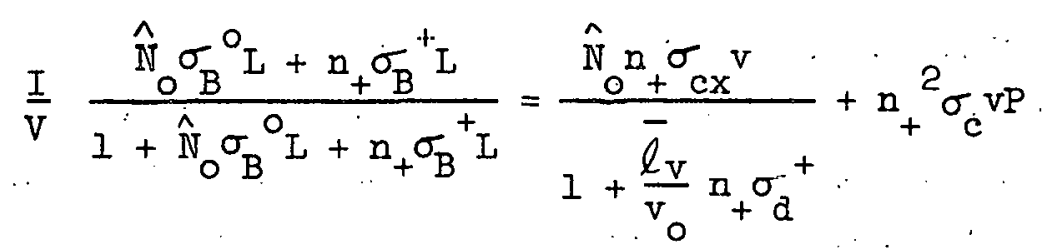

An expression for $\hat{N}_{0}$, the neutral density exterior to the plasma may be readily obtained by accounting for all the sources of gas. The background gas is assumed to come from a steady outgassing of the walls of the container and from backstreaming of neutrals resulting from the energetic ions and molecular ions which are injected and which finally strike the walls. We assume that a certain fraction $\Gamma$ of the input molecular ion ultimately enter the vacuum region as neutral atoms. Of course this is a rather crude accounting and does not distinguish between the different re-entry probabilities of energetic lons and unbroken-up molecular ions which strike the wall. By conservation of atoms, we see that $\Gamma \leq 2$. The steady outgassing rate of the surface is denoted by $\alpha \overline{\mathrm{S}}$ where $\overline{\mathrm{S}}$ is the surface area of interest and $\alpha$ is the outgassing rate per unit area.

'Mils influx of gas is balanced in two ways. First, neutrals are pumped off directly by extermal pumps acting on the system. If $\theta$ denotes the pumping speed of the external pumps, this loss rate is $\theta \hat{N}_{0^{*}}$ The second loss is due

5. R. F. Post, Proc. Second Geneva Conf. 31, 248 (1958). 
to the "ion-pumping" action of the trapped plasma. Every neutral atom which enters the plasma volume and undergoes either an ionization or a charge exchange becomes a slow ion. This ion is trapped on a field line and rapidly moves out to the mirror regions. A large fraction of these slow ions may be permanently trapped and prevented from returning to the vacuum region, for instance by accelerating them into a titanium plate and continually evaporating new layers of titanium on that region. This is one possible form of "ion-pumping." Let $\sigma$ denote the fractional probability that a slow ion does not return as a neutral. The rate of loss of neutrals by this mechanism is then:

$$
=\sigma \frac{\hat{N}_{o} n_{+} \sigma_{d}^{+} v}{1+\frac{\bar{l}_{v}}{v_{o}} n_{+} \sigma_{d}^{+}} v
$$

The resultant steady state equation for $\hat{\mathrm{N}}_{0}$ is then:

$$
\Gamma I+\alpha \bar{S}=\theta \hat{N}_{0}+\frac{\sigma \hat{N}_{0} n_{+} \sigma_{d}^{+} v V}{I+\frac{\bar{l}_{v}}{v_{0}} n_{+} \sigma_{d}^{+}}
$$

Now initially, in the absence of any input beam, the balance equation was

$$
\alpha \overline{\mathrm{S}}=\theta \mathrm{N}_{\mathrm{O}}
$$

where $N_{0}$ is the initial neutral density in the vacuum region before injection begase. Substituting Eq. (12) in Eq. (11), we have

$$
\hat{\mathrm{N}}_{0}=\frac{\frac{\Gamma}{\theta} I+\mathrm{N}_{0}}{1+\frac{\sigma}{\theta} \frac{\mathrm{n}_{+} \sigma_{\mathrm{d}}^{+} \mathrm{vV}}{1+\frac{\bar{l}_{\mathrm{v}}}{\mathrm{v}_{0}} \mathrm{n}_{+} \sigma_{\mathrm{d}}^{+}}}
$$


Equations (10) and (13) combined constitute an implicit equation in the variables $n_{+}$and $I$. (Some of these last considerations on backstreaming and ion pumping have not been included in previous publications ${ }^{l, 2}$ on burnout in DCX. This is done here in Appendix B.)

II. THE INJECTED CURRENT AS A FUNCTION OF THE ION DENSITY We wish to determine the variation of ion density $n_{+}$with changes in the injected current $I$. The gross features of the variation may be obtained by an algebraic analysis. Equations (10) and (13) combined have the general form:

$$
f\left(n_{t}, I\right)=0
$$

Let us first determine the possible roots of this equation for fixed $\mathrm{n}_{+}$. We shall rewrite Eq. (14) so as to explicitly display it as a polynomial in I. From Eq. (10) we have:

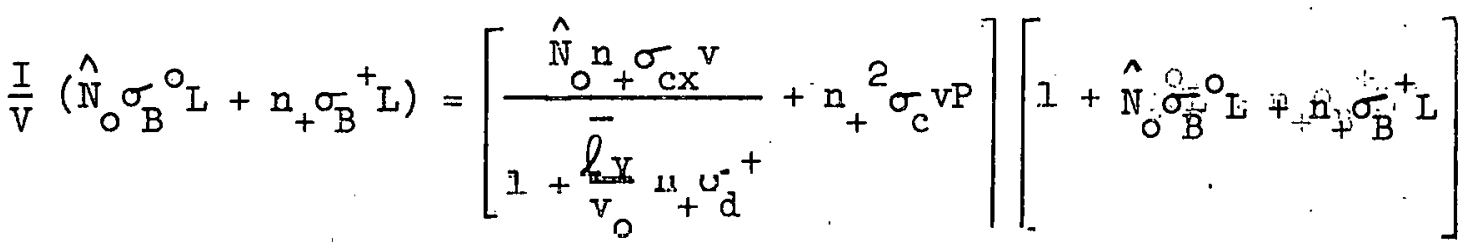

which has the general form, by Eq. (13),

$$
\frac{I}{V}(A I+B)=(C I+D)(I+A I+B)
$$

where $A, B, C$, and $D$ are positive definite quantities and are independent of $I$. Equation (i6) may be written

$$
I^{2}\left[\frac{A}{V}-A C\right]+I\left[\frac{B}{V}-C(x+B)-A D\right]-D(I+B)=0
$$

Two cases may be distinguished: 
a. $\frac{\mathrm{l}}{\mathrm{V}}>\mathrm{C}$ : In this case the product of the two roots is negative. Hence there is one positive real root and one negative real root. b. $\frac{1}{\mathrm{~V}}<\mathrm{C}$ : The coefficient of $\mathrm{I}$ in $\mathrm{Eq}$. (17) may be written as:

$$
=B\left(\frac{1}{V}-C\right)-C-A D
$$

Hence, in this case, it is negative. We ssee that the product of the roots is positive but that the sum of the roots is negative. This can only occur if the two roots are either both negative real or form a complex pair. There is no positive real root. " Hence, we see that there can be at most one positive real value of I for a given $n_{+}$:

\section{THE ION DENSITY AS A FUNCTION OF THE INJECTED CURRENT}

Let us now rewrite Eq. (15) in order to display it as a polynomial in $n_{+} \cdot$ We define the quantity $K$ as,

$$
K=\frac{\overline{l v}_{\mathrm{v}}}{\mathrm{v}_{0}} \sigma_{\mathrm{d}}^{+}+\frac{\sigma}{\theta} \sigma_{\mathrm{d}}^{+} \mathrm{vv}
$$

and multiply through by $\left(1+K_{+}\right)^{2}$ in Eq. (15). The result is:

$$
\begin{aligned}
& \frac{I}{\mathrm{~V}} \cdot\left[\left(\frac{\Gamma}{\theta} I+N_{0}\right)\left(I+\frac{\overline{l v}_{\mathrm{v}}}{v_{0}} \sigma_{d}^{+} n_{+}\right) \sigma_{B}{ }^{2}+n_{+} \sigma_{B}^{+} L\left(I+K_{n_{+}}\right)\right]\left(I+K_{n_{+}}\right)= \\
& =\left[\left(\frac{\Gamma}{\theta} I+N_{0}\right) n_{+} \sigma_{c x} v+n_{+}{ }^{2} \sigma_{c} v P\left(I+k_{n_{+}}\right)\right] . \\
& {\left[\left(1+n_{+} \sigma_{B}^{+} L\right)\left(1+K_{+}\right)+\left(\frac{\Gamma}{\theta} I+N_{0}\right) \sigma_{B}^{\circ} I\left(I+\frac{\overline{l v}_{v}}{v_{0}} n_{+} \sigma_{d}^{+}\right)\right]}
\end{aligned}
$$

which has the general form: 


$$
\mathrm{An}_{+}^{5}-\mathrm{Bn}_{+}^{4}+\mathrm{Cn}_{+}^{3}-\mathrm{Dn}_{+}^{2}+\mathrm{Bn}+\mathrm{F}=0
$$

Here

$$
\begin{aligned}
& A=\sigma_{c} \mathrm{vP} K^{2} \sigma_{B}^{+} L \\
& B=-\sigma_{c} v P K\left[\sigma_{B}^{+} I+K+\left(\frac{\Gamma}{\theta} I+N_{0}\right) \sigma_{B}^{0} I \frac{\ell_{v}}{v_{0}} \sigma_{d}^{+}\right] . \\
& F=\frac{I}{V}\left(\frac{\Gamma}{0} I+N_{0}\right) \sigma_{B}^{0} \dot{L}
\end{aligned}
$$

We see immediately that the product of the roots is positive and that the sum of the roots is negative. It follows at once that there is either only one positive real root or three positive real roots for $n_{+}$for a given value of $I$.

The results of Sections II and III enable us to sketch the general variation of $n_{+}$with $I$ and this is shown in Fig. 1 . The curve has the general form of an s-curve. 6 It should be noted that the root analysis given above does not exclude the possibility that the s-curve behavior will. occur several times instead of just once as shown in Fig. 1. The physical interpretation of the s-curve given in the next section makes it clear, however, that an s-curve will occur only once if at all. In this regard, it should be noted that in some cases no s-curve appears and instead the curve increases monotonically to a limiting value of $n_{+}$. The criterion for the occurence of this behavior is given below [see $\mathrm{kq} . \stackrel{+}{(32)}]$.

For comparison, the characteristic curve of $n_{+}$versus $I$ in the case of a fixed breakup device such as DCX is shown in Fig. 2.

6. A recent paper by I. N. Golovin (Harweli, April 1959, unpublished) states that Kumnetsov and coworkers have numerical results indicating a behavior of this sort. 
$-9-$

UNCLASSIFIED

ORNL-LR-OWG 39282

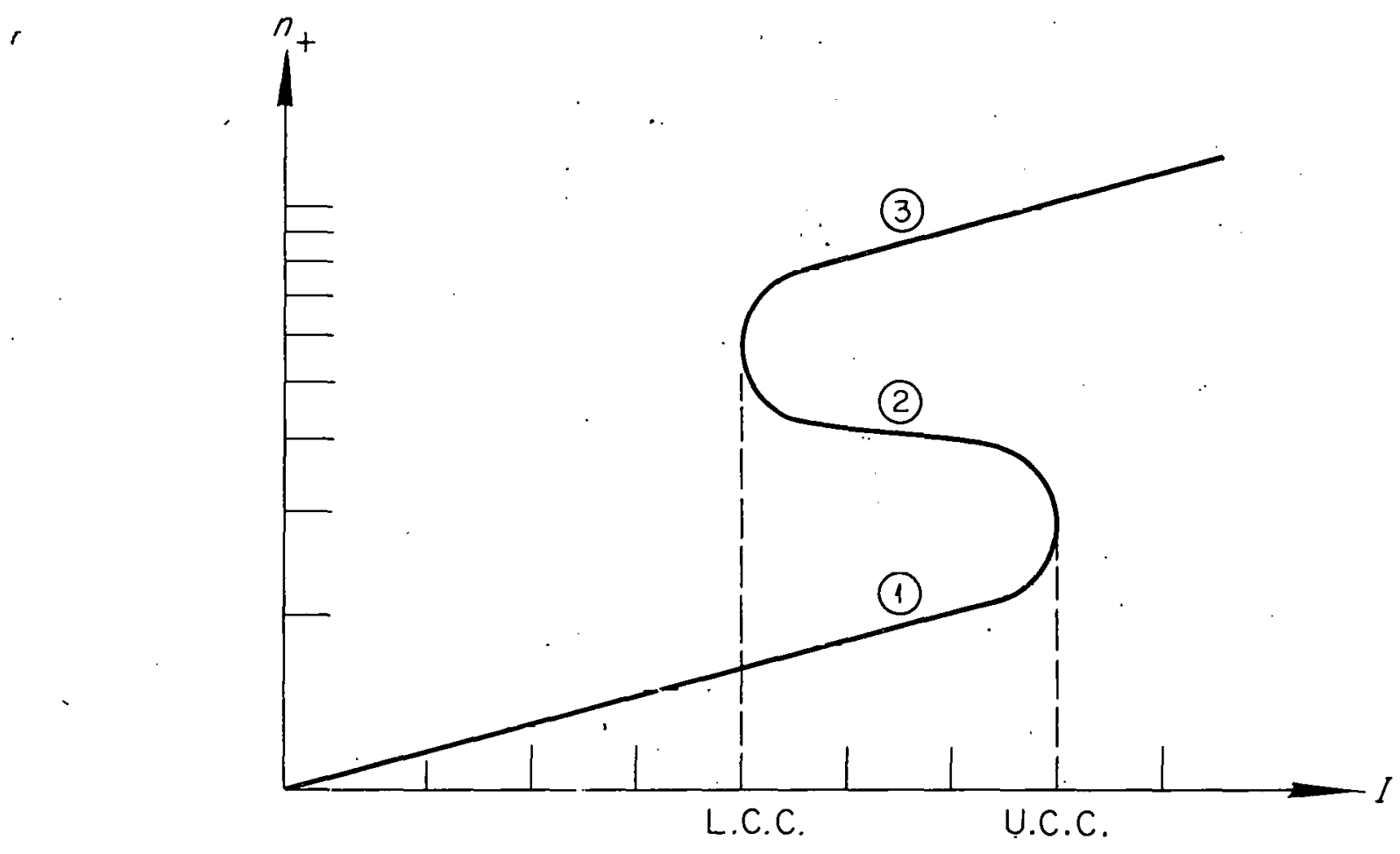

Fig. 1. Variation of Steady State Ion Density with Injected Current for an OGRA-Type Device. 
$-10-$

UNCLASSIFIED

ORNL-LR-OWG 39283

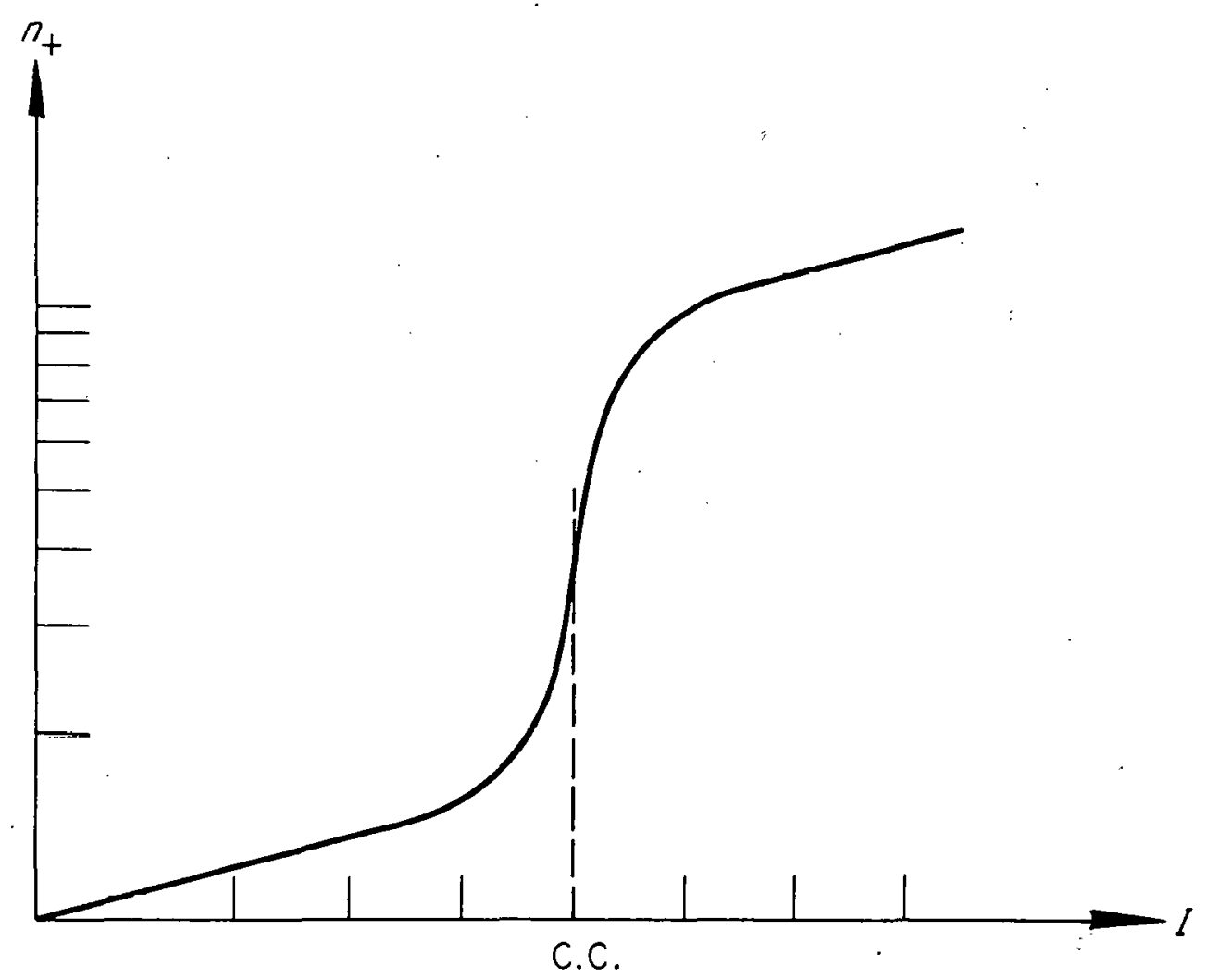

Fig. 2. Variation of Steady State Ion Density with. Injected Current for a DCX-Type Device. 


\section{PHYSICAL INTERPRETATION OF THE ROOTS}

The multiple roots occurring in Fig. I have a straightforward physical interpretation. In region I neutral burnout has set in. The steady state solution is achieved by balance between charge exchange loss of the trapped ions and feed by breakup of the molecular ions on the neutral background (mirror loss is negligible). The second solution in region 2 corresponds to the point at which the ion density has risen and the neutral density has fallen such that the breakup on the lons now is the same ar the previous breakup on the neutral gas. The charge exchange loss remains the saine since it is proportional to the product $n_{0} n_{+}$(where $n_{0}$ is the average neutral density in the plasma region) and since, after burnout, $n_{0} \sim 1 / n_{+}$. The final root of region 3 corresponds to the point at which mirror loss becomes more important than charge exchange loss.

The physical interpretation just given makes it clear that roots $I$ and 3 are stable while root 2 is unstable. For example, suppose the system is in steady-stats $\because \cdots$ equilibrium at root 1 and that there is then a slight transient increase in the trapped ion density. The trapping rate will not increase appreciably since it is determined by the neutral gas density while the charge exchange loss rate increases linearly with $\mathrm{n}_{+}{ }^{\circ}$ Hence the ion density will decrease and this root is stable. If the system is in equilibrium at root 2 , the reaction to this increase is quite different. The trapping rate increases linearly with $\mathrm{n}_{+}$since trapping is now primarily by collision with ions while the charge exchange loss rate (beyond burnout) remains constant. Hence the lon density will continue to increase and the root is unstable. Finally consider the effect of a transient increase at root 3 . The trapping rate increases linearly but the dominant mirror loss rate increases quadratically. Hence the ion density decreases and this root is stable. 
V. THE UPPER CRITICAI CURRENT (UCC)

Of course we can stop at this point and analyze the behavior of any given device by obtaining a curve such as in Fig. I from Eqs. (10) and (13) by numerical means. This is somewhat laborious, particularly if we wish to do a parameter survey and compare various proposals. Instead of the entire curve in Fig. 1, it would be almost as useful to know the two points at which the curve is vertical. These are denoted as the Upper Critical Current (UCC) and Lower Critical Current (ICC) in Fig. I. It is clear that it is necessary to attain the UCC in order to build up a high density plasma when the density is being increased from below. On the other hand, once a high density has been achieved, it may be maintained by steady injection of a current larger than the LCC. A derivation of an approximate expression for the UCC is given below and one for the ICC is given in the next section.

Let us consider I as a function of $n_{+}$and differentiate Eq. (14). We have:

$$
\frac{\partial f}{\partial n_{+}}+\frac{\partial I}{d n_{+}} \frac{\partial f}{\partial I}=0
$$

Now the UCC and ICC are distinguished by being the points at which $\mathrm{dI} / \mathrm{dn}_{+}=0$. Hence we have

$$
\frac{\partial f}{\partial n_{+}}=u
$$

The UCC and LCC are determined by the simultaneous solution of Eqs. (14) and (22). Substituting in Eq. (22) from Eq. (10), we have 


$$
\begin{aligned}
& \frac{\partial}{\partial n_{+}}\left[\frac{I}{V} \frac{\hat{N}_{o} \sigma_{B}^{o} L+n_{+} \sigma_{B}^{+} L}{I+\hat{N}_{0} \sigma_{B}^{o} L+n_{+} \sigma_{B}^{+} L}\right]=\frac{\partial}{\partial n_{+}}\left[\frac{\hat{N}_{0} n_{+} \sigma_{c x} v}{1+\frac{l v}{v_{o}} n_{+} \sigma_{d}^{+}}+n_{+}^{2} \sigma_{c} v P\right] \\
& =\frac{\partial}{\partial n_{+}}\left[\frac{\left(\frac{\Gamma}{\theta} I+N_{0}\right) n_{+} \sigma_{c x} v}{I+k n_{+}}+n_{+}^{2} \sigma_{c} v P\right]
\end{aligned}
$$

where $K$ is defined in Eq. (18).

To get an expression for the UCC we neglect the second term on the right side of $\mathrm{Eq}$. (23). This corresponds to mirror loss and should be negligible according to the physical interpretation given earlier. To get a relatively simple result we must make one other approximation. We assume that the UCC is well above burnout, or in other words, that $K_{n_{+}}>>1$ at that point. To first approximation, then, the bracket on the right hand side of Eq. (23) is independent of $\mathrm{n}_{+}$and its partial derivative vanishes. Equation (23) becomes

$$
\frac{\partial}{\partial n_{+}}\left[\frac{\hat{N}_{0} \sigma_{B}{ }^{o} L+n_{+} \sigma_{B}^{+} L}{1+\hat{N}_{0} \sigma_{B}{ }^{o} L+n_{+} \sigma_{B}^{+} L}\right]=0 .
$$

Now

$$
\frac{d}{d x}\left(\frac{y}{1+y}\right)=\frac{\frac{d y}{d x}}{(1+y)^{2}}
$$

Hence Eq. (24) reduces to

$$
\frac{\partial}{\partial n_{+}}\left(\hat{N}_{0} \sigma_{B}^{o} L+n_{+} \sigma_{B}^{+} L\right)=0
$$

or 
14

$$
\frac{\partial}{\partial n_{+}}\left[\frac{\left(\frac{\Gamma}{\theta} I+N_{0}\right) \sigma_{B}{ }^{\sigma} L\left(I+\frac{l_{v}}{v_{0}} n_{+} \sigma_{d}^{+}\right)}{\left(1+K n_{+}\right)}+n_{+} \sigma_{B}^{+} I\right]=0
$$

After some algebra, this equation reduces to:

$$
\left(I+\gamma_{n_{+}}\right)=\sqrt{\frac{\left(\frac{\Gamma}{\theta} I+N_{o}\right) \sigma_{B}^{0}}{\sigma_{B}^{+}}\left(\frac{\sigma}{\theta}\right) \sigma_{d}^{+} v V \equiv \phi}
$$

or

$$
n_{+}=\frac{\phi-1}{K}
$$

We can now eliminate $n_{+}$in $\mathrm{Eq}$. (14) by use of Eq. (29). The result is an implicit equation in I, whose solution should be the UCC. This equation is easily found to be:

$$
I=\frac{\left(\frac{\Gamma}{\theta} I+N_{0}\right) \sigma_{c x} v V\left(\frac{\phi-I}{\phi}\right)\left[1+\Lambda \sigma_{B}{ }^{o} L\left(\frac{\phi-I}{K}\right) \sigma_{B}{ }^{+} L\right.}{\gamma_{L}\left[\Lambda \sigma_{B}{ }^{o} L+\left(\frac{\phi-I}{K}\right) \sigma_{B}{ }^{+} L\right]}
$$

where

$$
\Lambda=\left(\frac{\Gamma}{\theta} I+N_{0}\right)\left[I+\left(\frac{\phi-I}{k}\right) \frac{\bar{l}_{\mathrm{v}}}{\mathrm{v}_{0}} \sigma_{\mathrm{d}}^{+}\right] \frac{1}{\bar{\phi}}
$$

The solution of Eq. (30) gives us the UCC and the corresponding value of $n_{+}$ is then given by Eq. (29).

It should be noted that we assumed initially that $K_{n_{+}}>1$ at the UCC. In order to be self-consistent; then, the value of $\phi$ corresponding to our solution should be large compared to unity. our numerical results seem to 
indicate that quite good answers are obtained for the UCC even when $\varnothing$ is of the order of 2. When $\phi$ is less than unity, the approximation breaks down completely and in this case we have found no simple relation which can be used.

It has not yet been demonstrated that there is only one real positive value of I which satisfies Eq. (30). We have succeeded in showing this in the limit of $\phi>>1$. The method is similar to that used earlier and consists in expressing Eq. (30) as a (3rd order) polynomial in $\varnothing$. It can be shown that one positive real solution for $\varnothing$ exists if

$$
\frac{\theta \bar{l}}{v_{0}}+\sigma>\Gamma \frac{\sigma_{c x}}{\sigma_{d}^{+}}
$$

If the inequality is reversed, there is no positive real root. From the definition of $\phi$, Eq. (28), we see that Eq. (32) is a necessary condition for the existance of an UCC.

One final point before leaving this section. If we make the opposite assumption to that made at the beginning of this section and take $K_{n}<<1$, it is then easy to show that no simultaneous solution of Eqs. (23) and (24) can exist. This verifies our physical understanding of the roots which requires that burnout occur in order that an UCC exist.

\section{THE LOWER CRITICAL CURRENT (ICC)}

The LCC is determined by the simultaneous solution of Eqs. (23) and (14). Our previous physical picture of conditions at the ICC indicated that the neutral background should be ent1rely negligible at that point. Hence we neglect the terms $\hat{N}_{q_{B}} \sigma^{\circ} \mathrm{L}$. compared to $n_{+} \sigma_{B}{ }^{+} \mathrm{L}$ in Eq. (23). Correspondingly we assume that $n_{+} \sigma_{B}^{+} L>1$ and $K_{n_{+}}>1$. Equation (23) becomes:

$$
\frac{\partial}{\partial n_{+}}\left[\frac{I}{V}\left(1-\frac{1}{n_{+} \sigma_{B}^{+} L}\right)\right]=\frac{\partial}{\partial n_{+}}\left[\frac{\left(\frac{\Gamma}{\bar{\theta}} I+N_{0}\right) \sigma_{c x}^{v}}{K}\left(1-\frac{1}{K n_{+}}\right)+n_{+}^{2} \sigma_{c}^{v P}\right]
$$


The solution of this equation is:

$$
\mathrm{n}_{+}^{3}=\frac{I}{2 \sigma_{C} v P}\left[\frac{I}{v \sigma_{B}{ }^{+} I}-\frac{\left(\frac{\Gamma}{\theta} I+N_{0}\right) \sigma_{c x} v}{k^{2}}\right] .
$$

which can be rewritten by use of Eq. (14) as:

$$
n_{+}=\left\{\frac{I}{3 \sigma_{c} v P}\left[\frac{I}{v}-\frac{\left(\frac{\Gamma}{\theta} I+N_{o}\right) \sigma_{c x} v}{K}\right]\right\}^{\frac{I}{2}} \equiv \delta
$$

Upon substitution in Eq. (14), we obtain an implicit equation in I,

$$
I=\frac{\left(\frac{\Gamma}{\theta} I+N_{0}\right) \sigma_{c x} \mathrm{vV}\left(1-\frac{3}{2 K \delta}\right)}{K\left(1-\frac{3}{2 \delta \sigma_{B}^{+} L}\right)}
$$

Just as in the case of the UCC, this expression is self-consistent only if the resulting solution is such that $K \delta>1$ and $\sigma_{B}^{+}+\delta>1$. Once again, in this limit, it is immediately demonstrated that there is at most one real positive root of $\mathrm{Eq}$. (36) and that this root exists only if the inequality of Eq. (32) is satisfied.

\section{NUMERICAL SOLUTIONS FOR "OGRA"}

A series of numerical runs was made using parameters which should be roughly that of the "OGRA" experiment. These parameters were:

$$
\begin{aligned}
& \mathrm{L}=10^{5} \mathrm{~cm} . \\
& \bar{l}=50 \mathrm{~cm} . \\
& \mathrm{V}=2.35 \times 10^{6} \mathrm{~cm}^{3} . \\
& \theta=4 \times 10^{7} \text { liters } / \mathrm{sec} . \\
& P=0.388 .
\end{aligned}
$$


Both $\mathrm{H}_{2}^{+}$and $\mathrm{D}_{2}^{+}$injection was considered, each at an energy of $200 \mathrm{kev}$. Furthermore, since there appear to be some large differences in published values, two sets of cross sections were used. One set, hereafter denoted by USSR, was taken from the curves of Federenko as given in reference 4. The other set, hereafter denoted as USA, were based on Barnett's results ${ }^{7}$ and the Bethe formula for the ionization cross section. 8 These cross sections (per gas atom) are tabulated below:

a. Deuterium:

$$
\begin{aligned}
& v_{0}=1.26 \times 10^{5} \mathrm{~cm} / \mathrm{sec} \\
& v=3.12 \times 10^{8} \mathrm{~cm} / \mathrm{sec} \\
& \sigma_{c} \cong 2.6 \times 10^{-22} \mathrm{~cm}^{2}
\end{aligned}
$$

USA

USSSR

\begin{tabular}{lrl}
\hline$\sigma_{B}^{0}$ & $5 \times 10^{-17}$ & $1.65 \times 10^{-16}$ \\
$\sigma_{B}^{+}$ & $5 \times 10^{-17}$ & $1.65 \times 10^{-16}$ \\
$\sigma_{c x}$ & $9 \times 10^{-17}$ & $7.5 \times 10^{-17}$ \\
$\sigma_{d}^{+}$ & $3.02 \times 10^{-16}$ & $2.6 \times 10^{-16}$ \\
\hline
\end{tabular}

b. Hydrogen:

$$
\begin{aligned}
v_{0} & =1.78 \times 10^{5} \mathrm{~cm} / \mathrm{sec} \\
v & =4.4 \times 10^{8} \mathrm{~cm} / \mathrm{sec} \\
\sigma_{c} & =2.6 \times 10^{-22} \mathrm{~cm}^{2}
\end{aligned}
$$

\begin{tabular}{lrr} 
& \multicolumn{1}{c}{ USA } & \multicolumn{1}{c}{ USSR } \\
\hline$\sigma_{\mathrm{B}}^{0}$ & $5 \times 10^{-17}$ & $1.3 \times 10^{-16}$ \\
$\sigma_{\mathrm{B}}^{+}$ & $5 \times 10^{-17}$ & $1.3 \times 10^{-16}$ \\
$\sigma_{\mathrm{cx}}$ & $1.2 \times 10^{-17}$ & $3 \times 10^{-18}$ \\
$\sigma_{\mathrm{d}}^{+}$ & $1.32 \times 10^{-16}$ & $1.08 \times 10^{-16}$ \\
\hline
\end{tabular}

7. C. F. Barnett and H. K. Reynolds, Phys. Rev. 108, 355 (1958).

8. N. F. Mott and H. S. W. Massey, The Theory of Atomic Collisions, Oxtord (1949) p. 247. 
Runs were made for a variety of values of the initial pressure $N_{0}$, as well as $\Gamma$ and $\sigma$. 'These' results are plotted in Figs. 15-26. In a few cases, exact solutions of Eqs. (10) and (13) were obtained. These are shown in Figs. 3-14. together with the values of UCC and LCC determined from Eqs. (30) and (36).

\section{SUMMARY}

It is shown that the general shape of the curve which plots steadystate ion density versus injected current is an s-curve (see Fig. 1) for a gas breakup trapping device such as OGRA. The actual curve may be calculated by numerical means by use of Eqs. (10) and (13). Approximate expressions are obtained for the two points at which the curve is vertical. The upper critical current (UCC) is the solution of the implicit Eqs. (30) and (31). The corresponding density is then calculated in Eq. (29). The lower critical current is the solution of the implicit Eqs. (36) and (35). The corresponding density is then given by Eq. (35). Burnout and the characteristic s-curve will only occur if the inequality of $\mathrm{Eq}$. (32). is satisfied. If not, there is simply a monotonic increase of the density to a limiting value as the current increases indefinitely.

A physical interpretation of these roots is given in Section IV. A numerical survey of UCC and ICC for an experimental device having the dimensions of the Ruissian OGRA are presented In Figs. 3-26. Appendlx A considers the effect of treating the path length $L$ as a fixed range rather than a mean free path and Appendix $B$ applies the ion pumping consideration to previous formulas for burnout in DCX. 


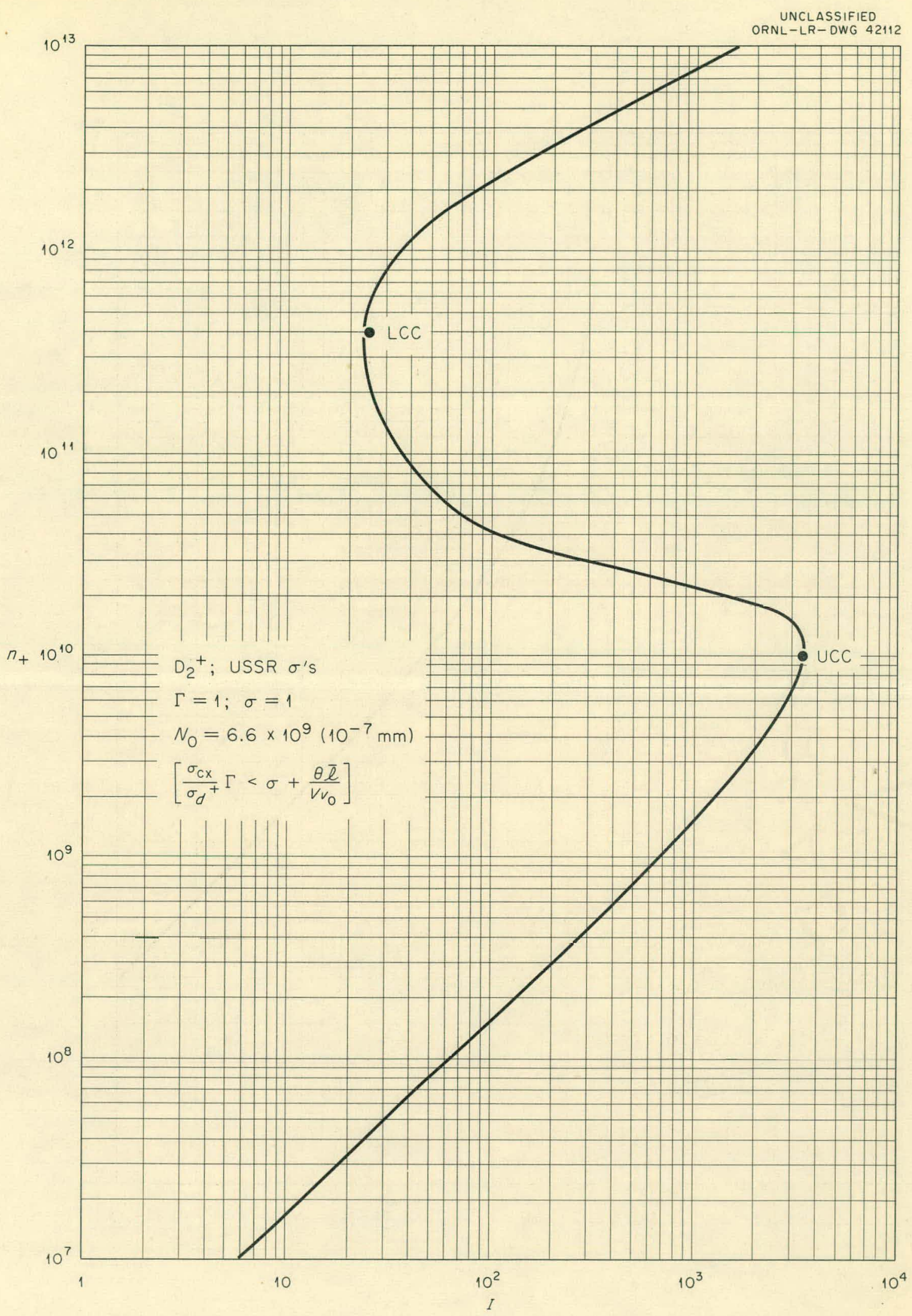

Fig. 3. 


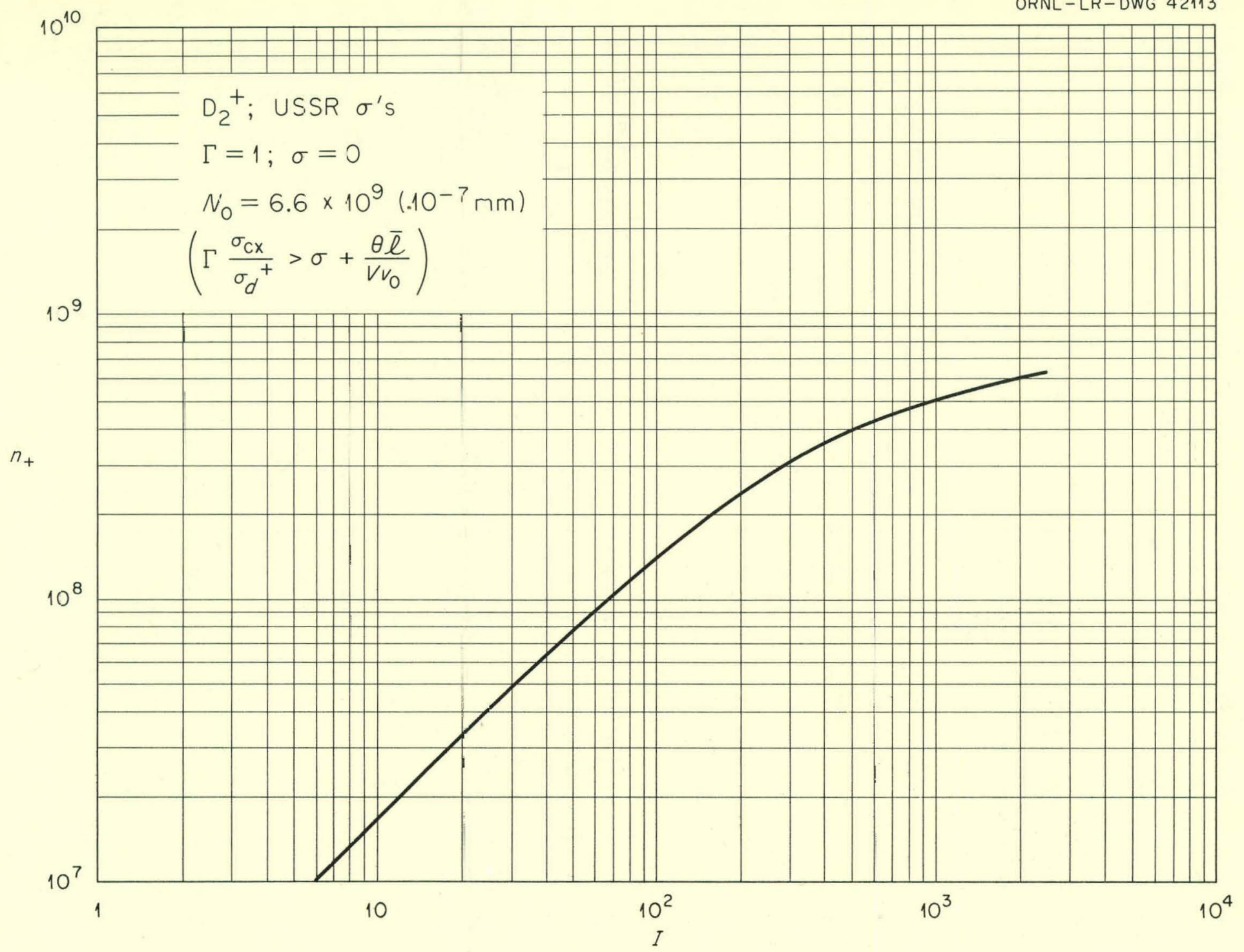

Fig. 4. 


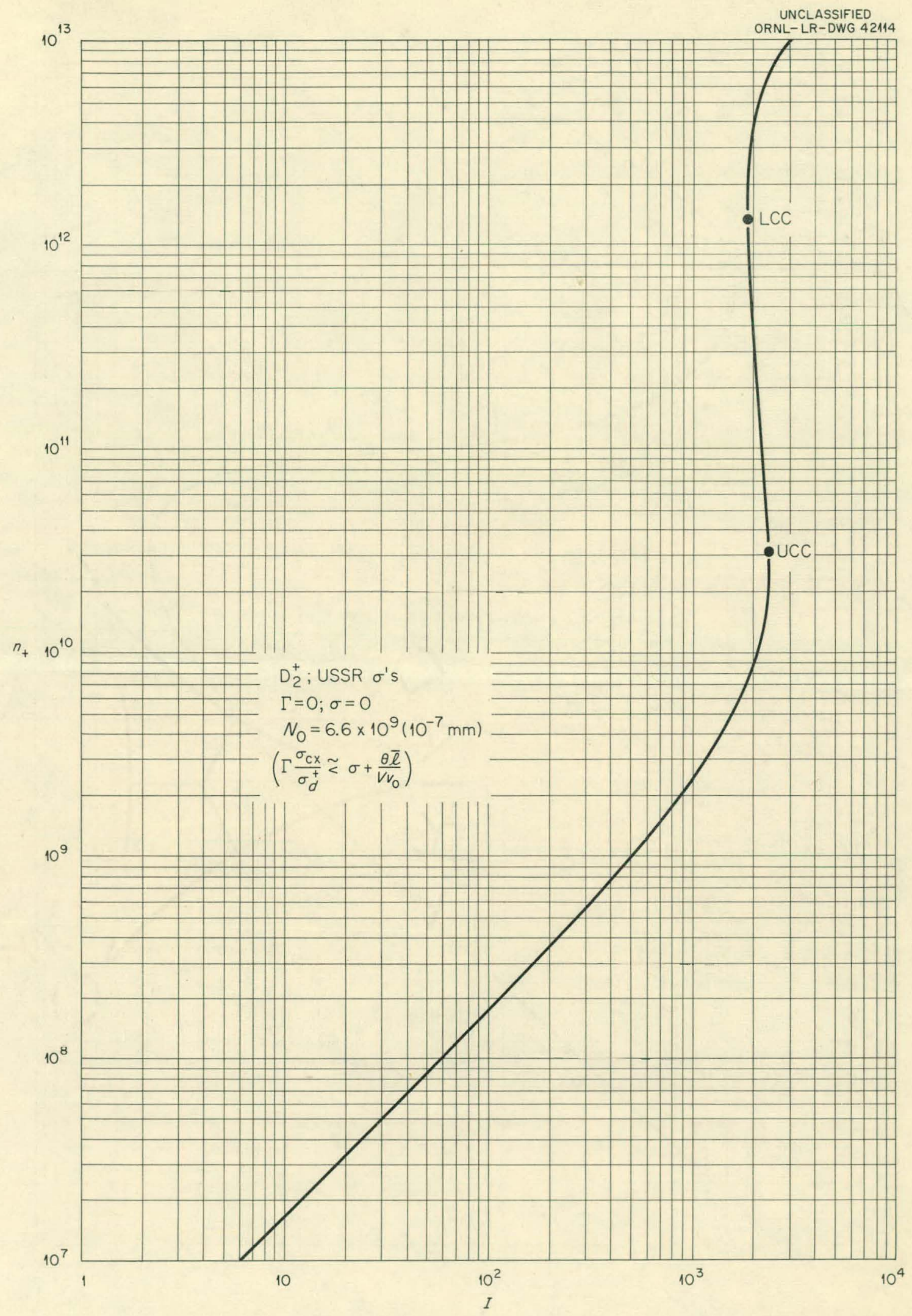

Fig. 5 . 


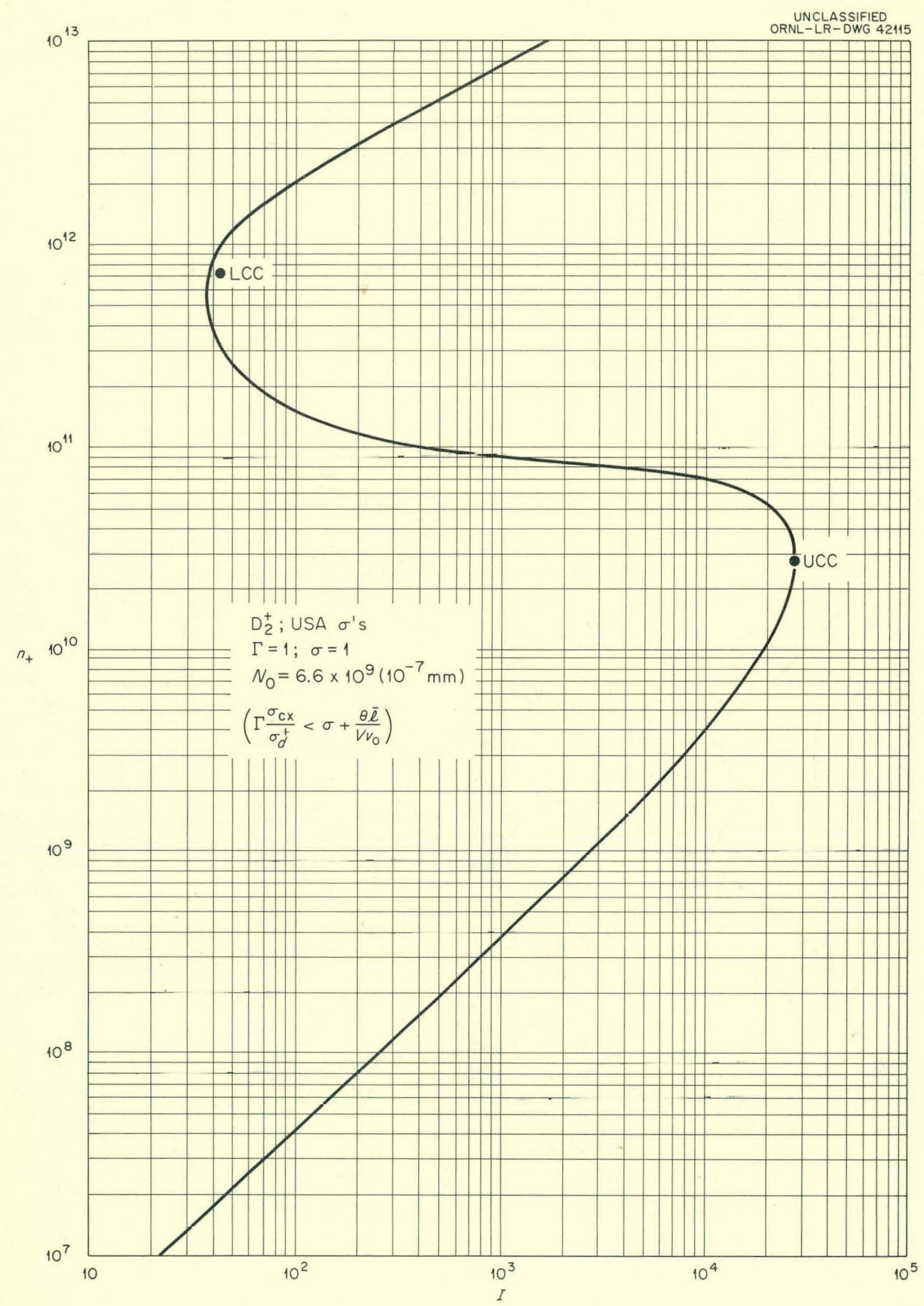

Fig. 6. 


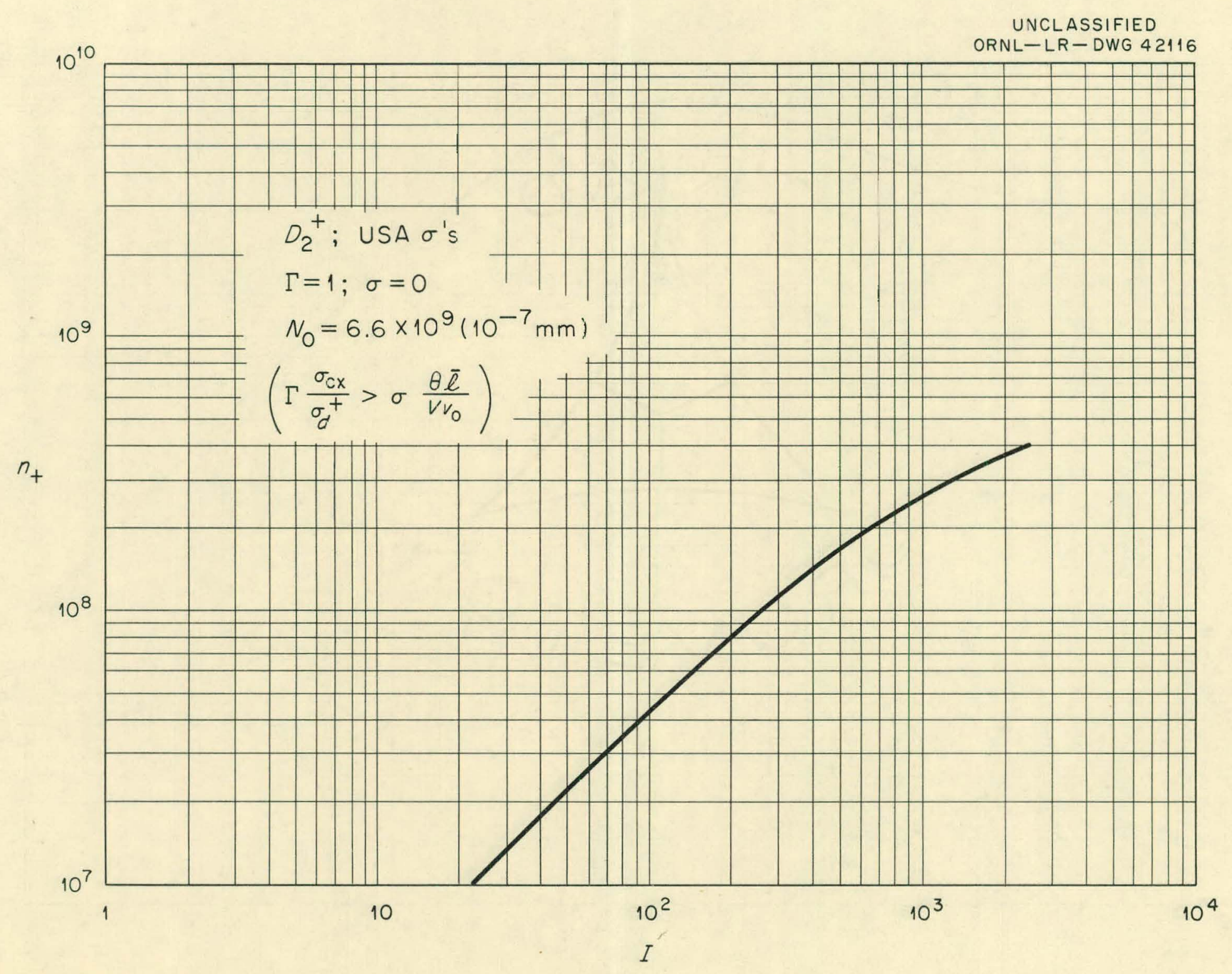

Fig. 7 . 


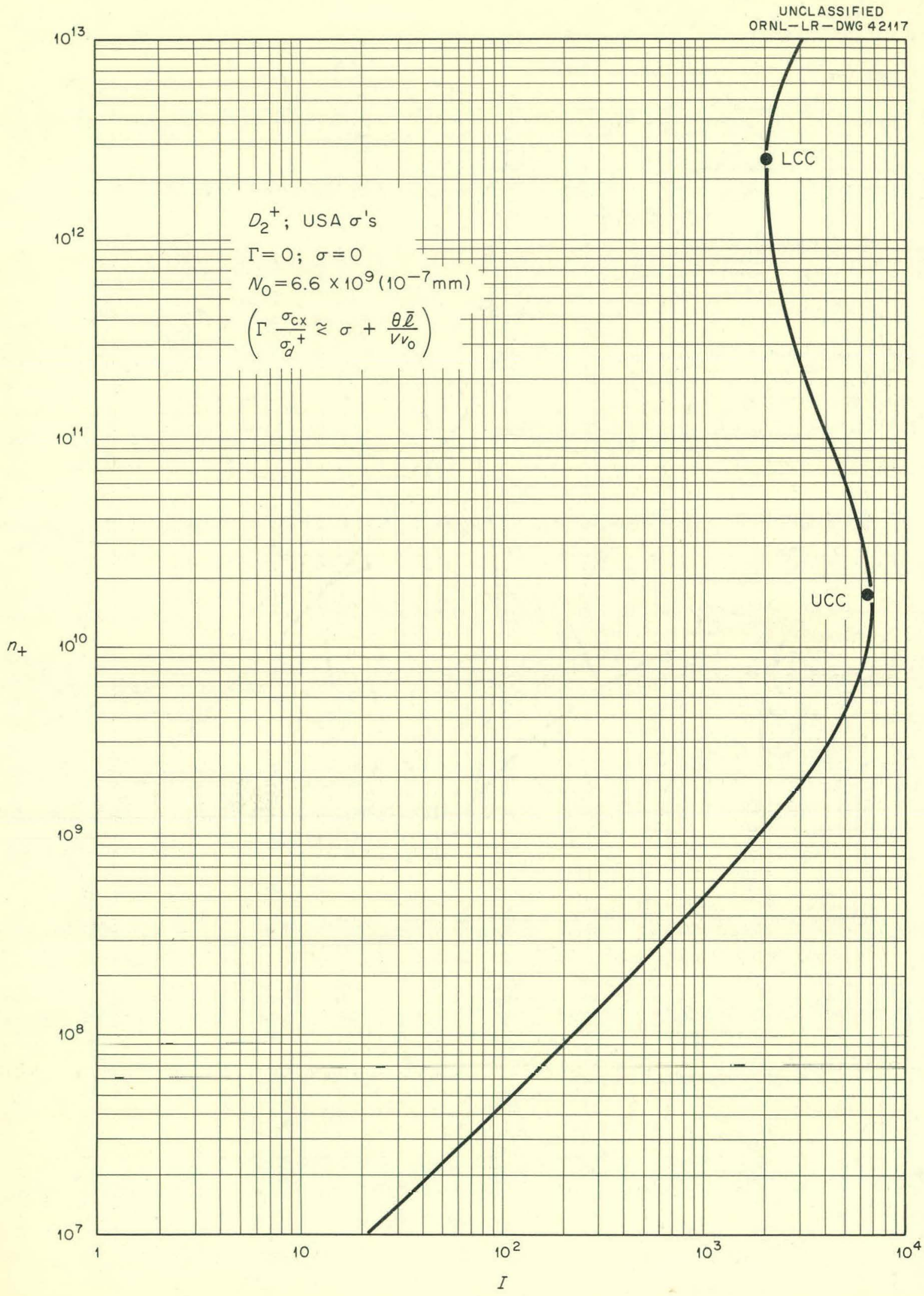

Fig. 8. 


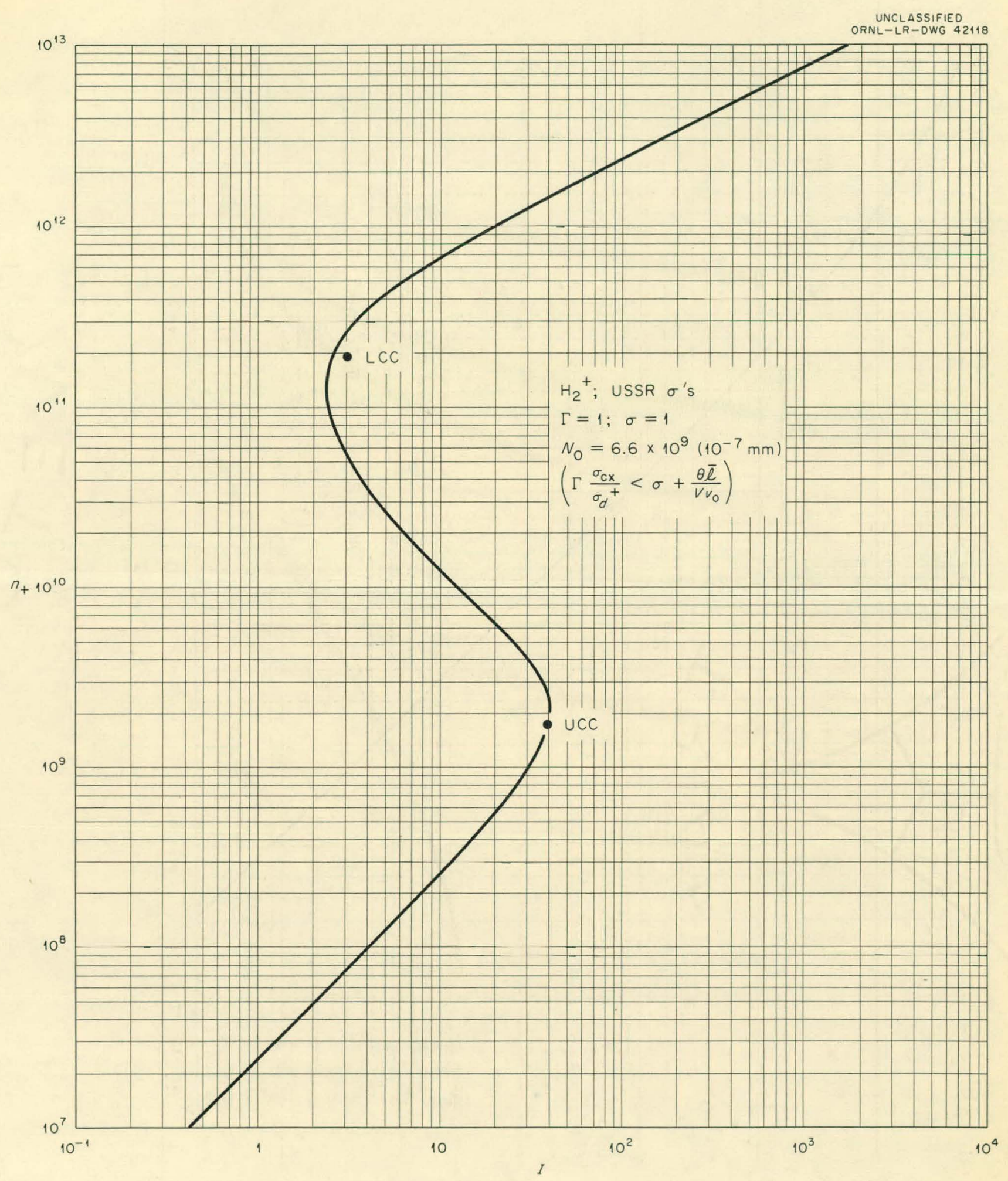

Fig. 9. 


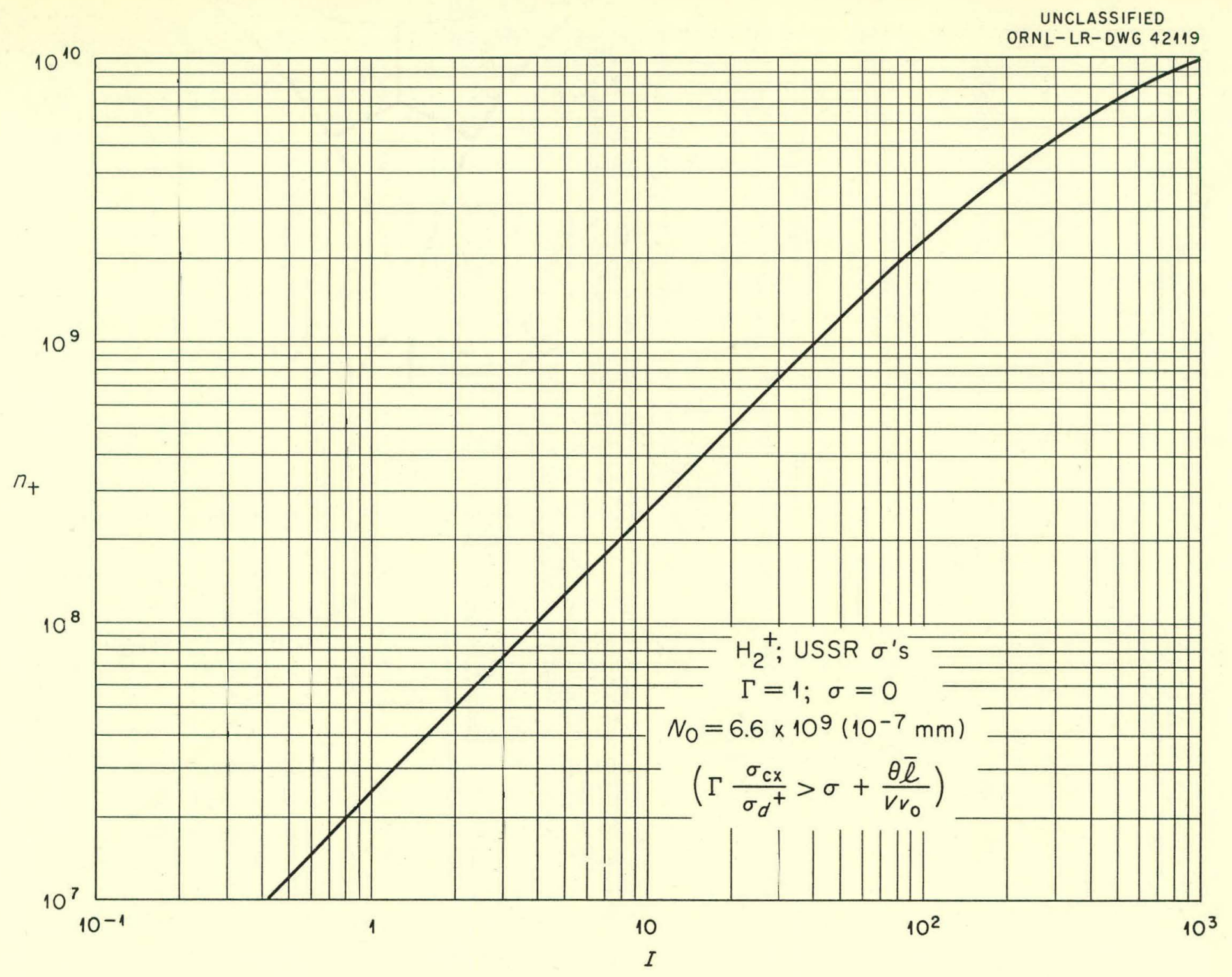

Fig. 10. 


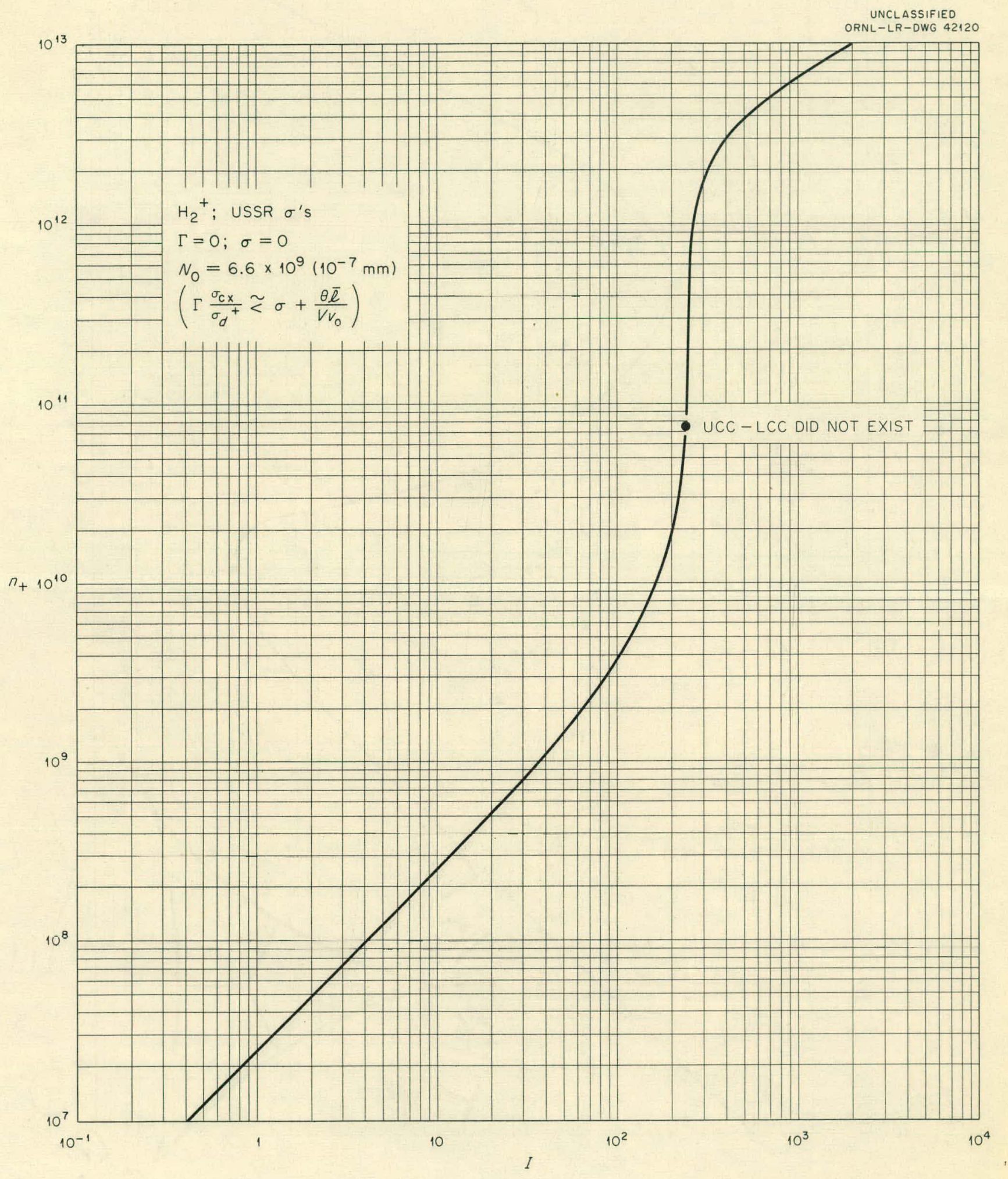

Fig. 11. 


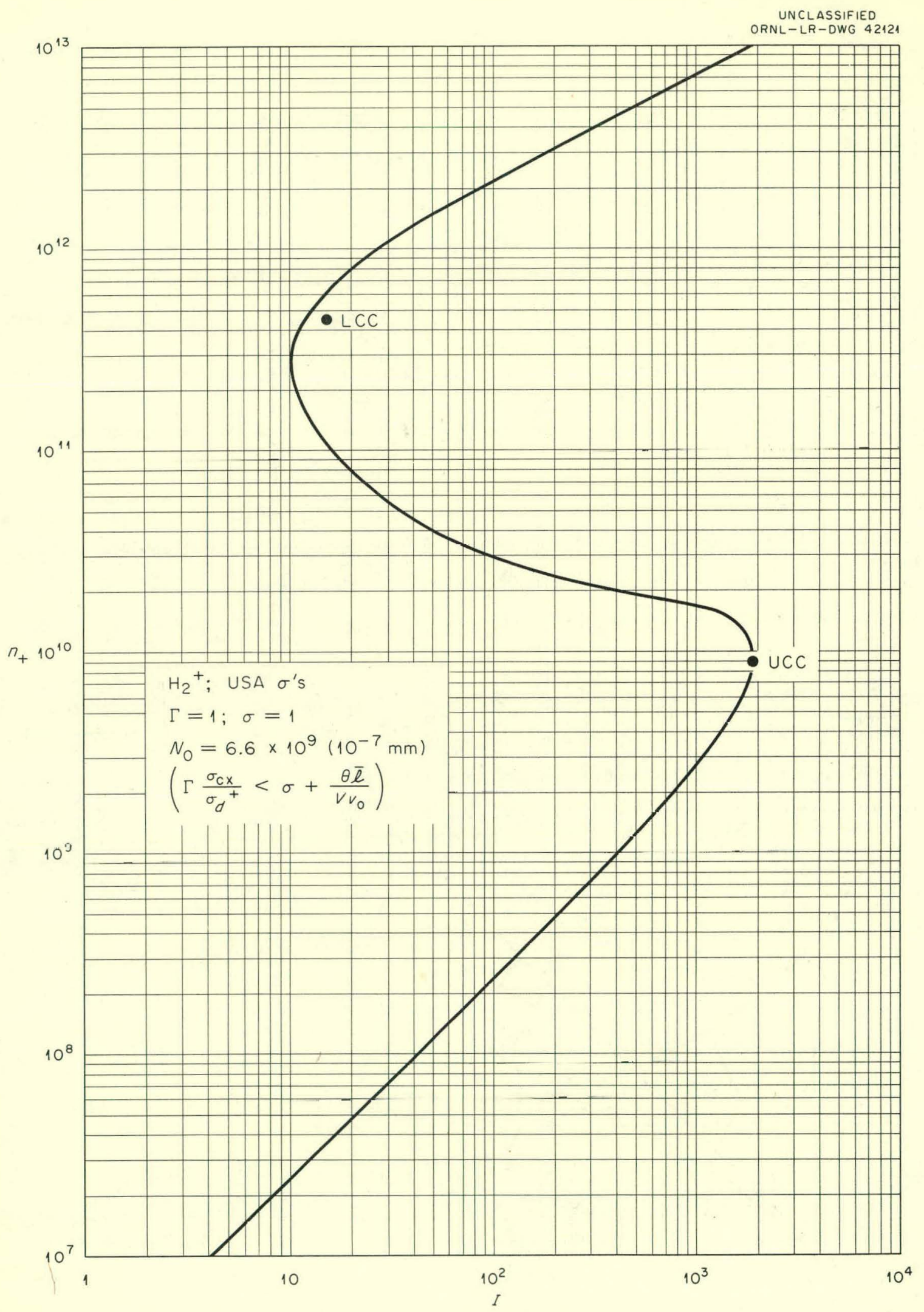

Fig. 12 . 


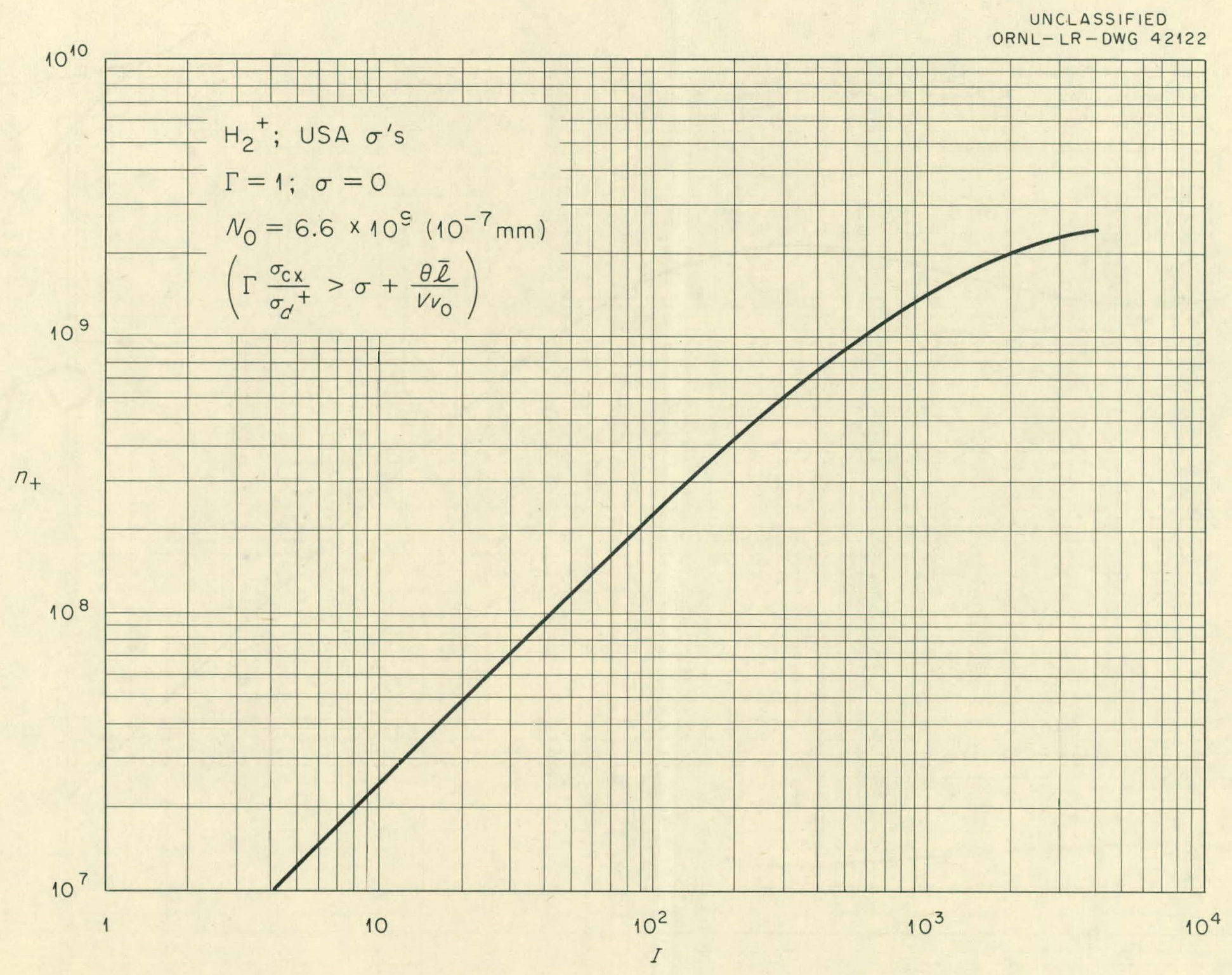

Fig. 13. 


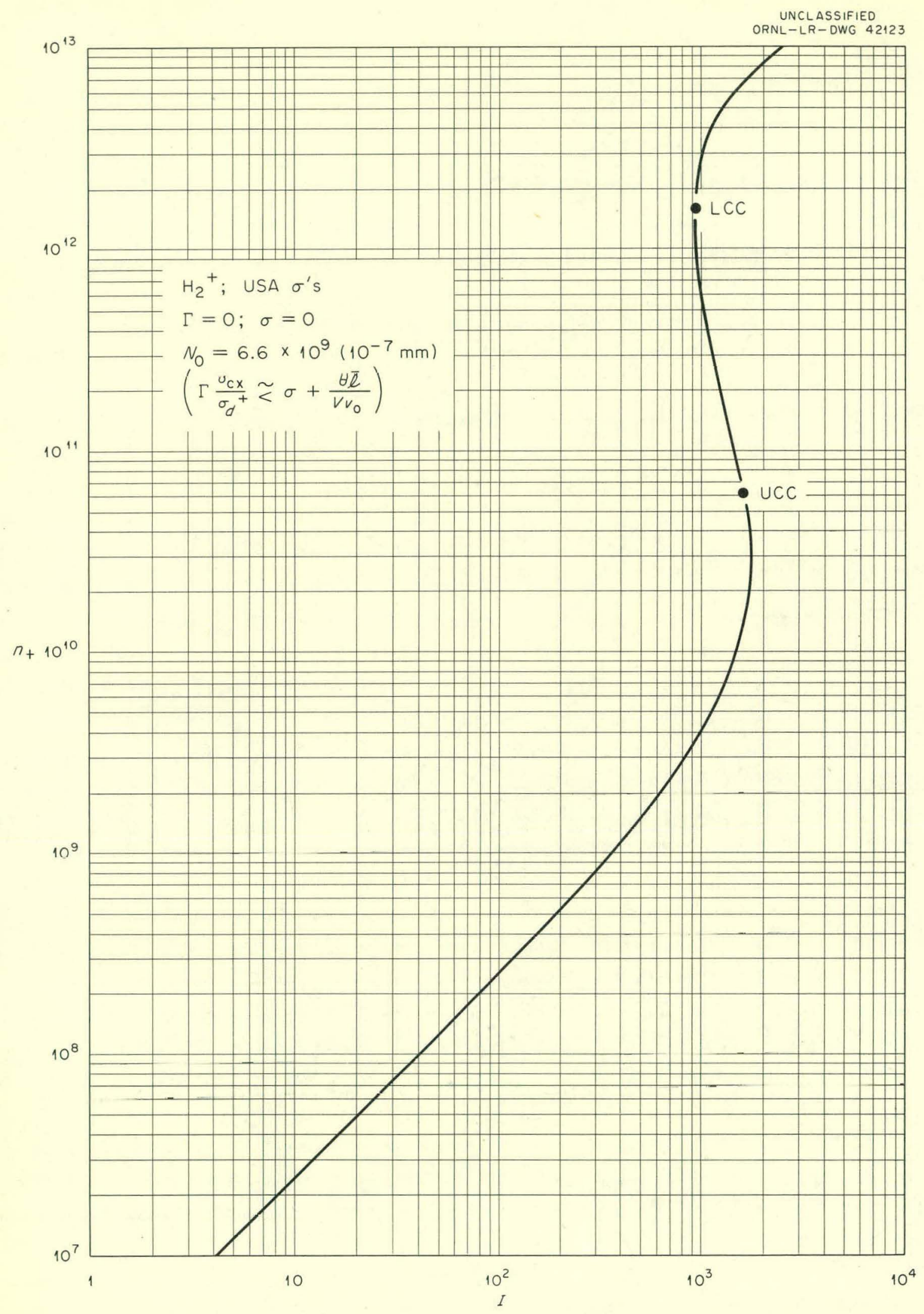

Fig. 14. 


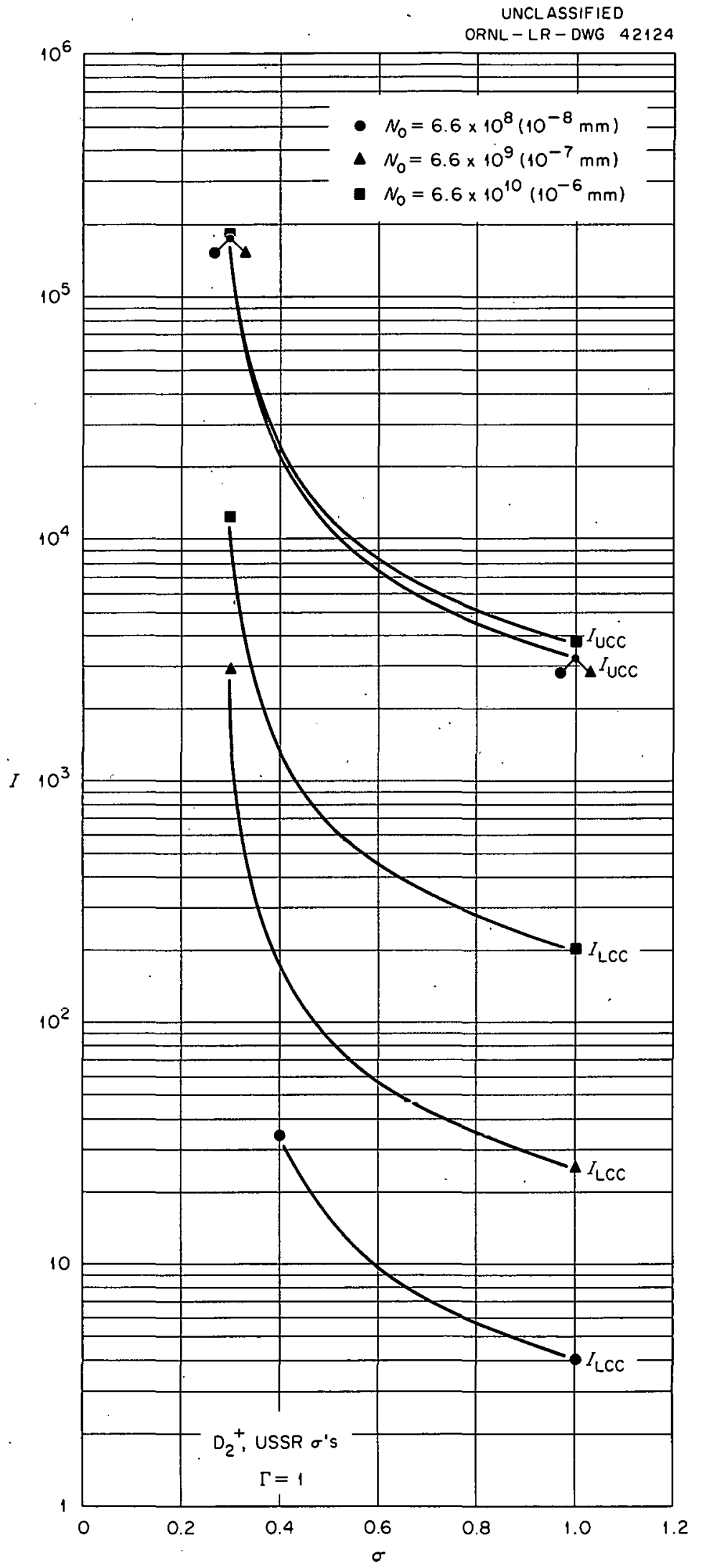

Fig. 15. 


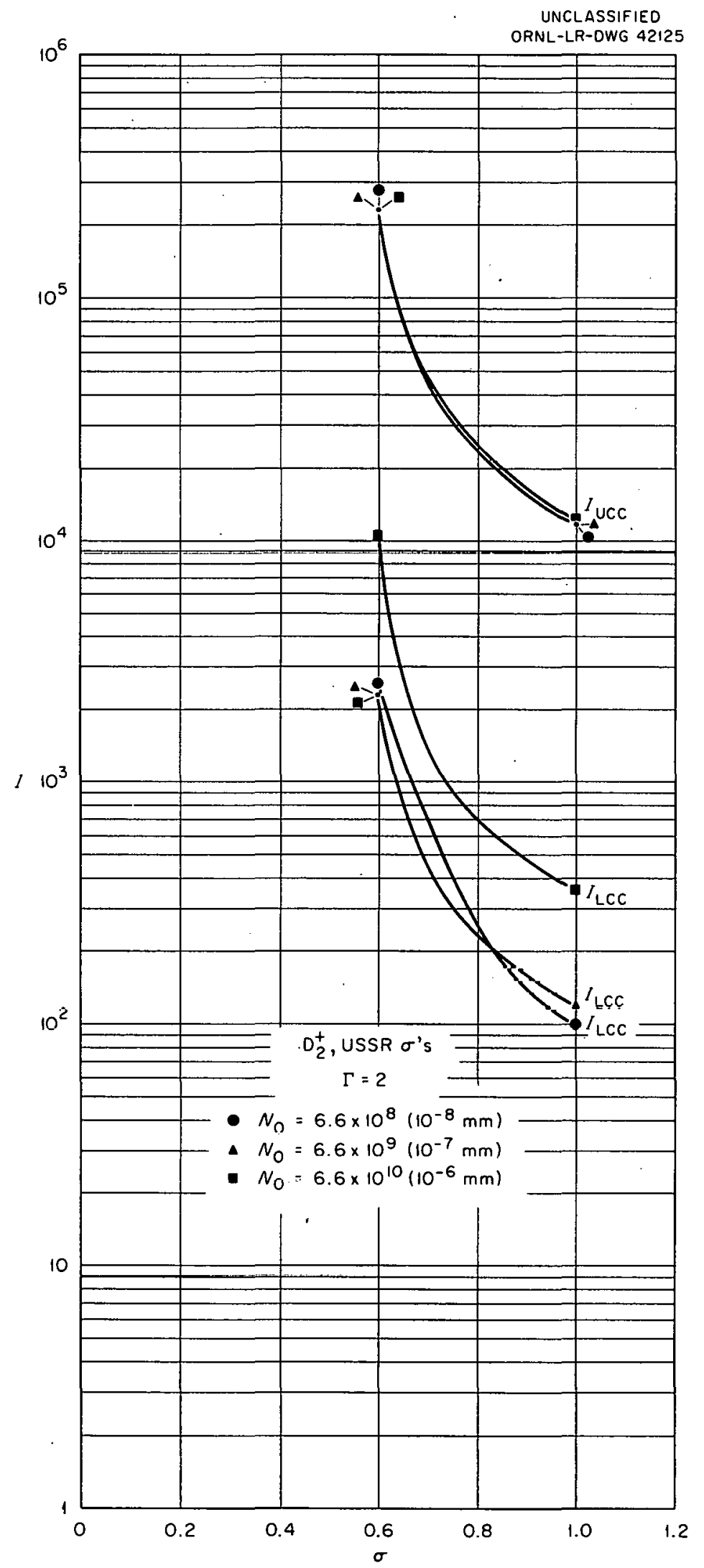

Fig. 16. 


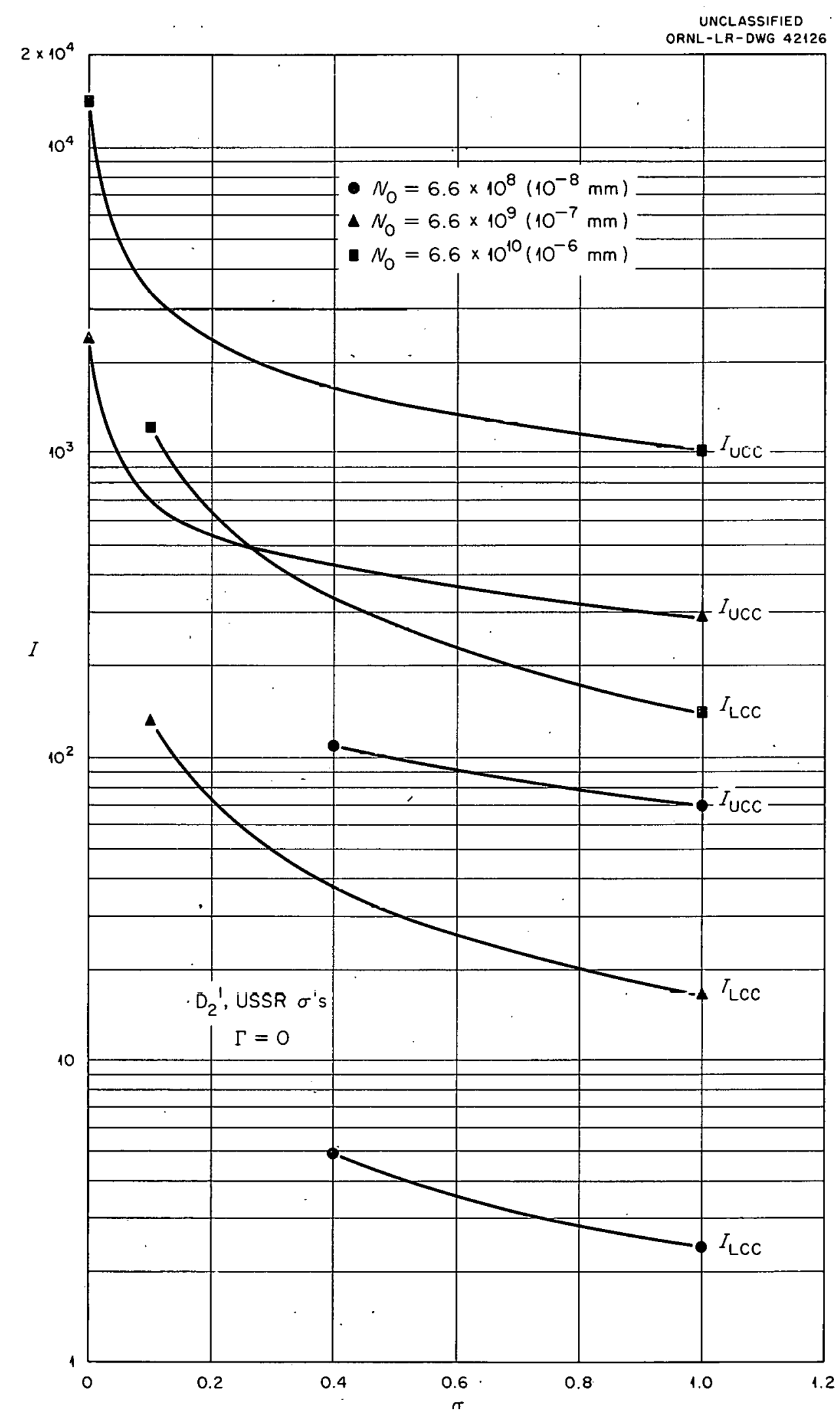

Fig. 17. 


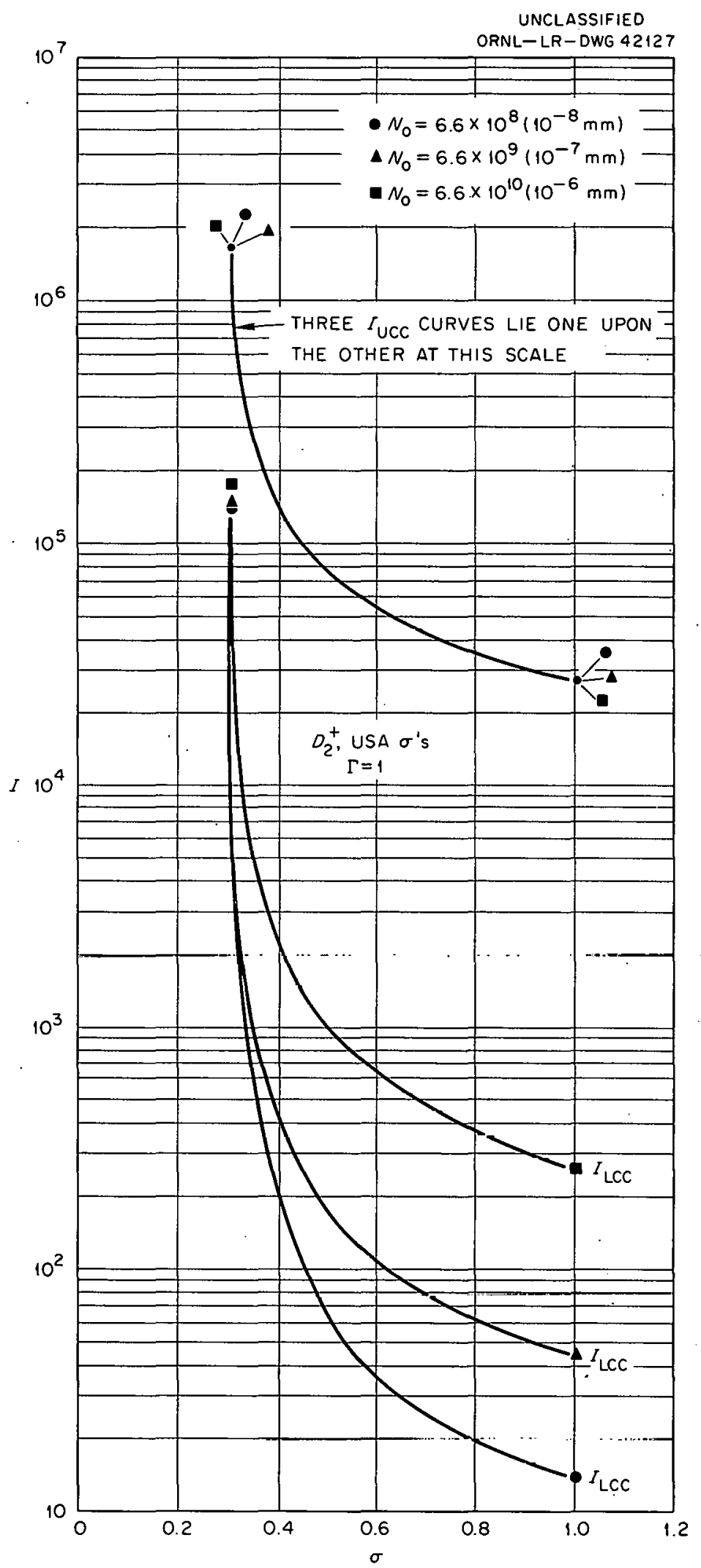

Fig. 18. 


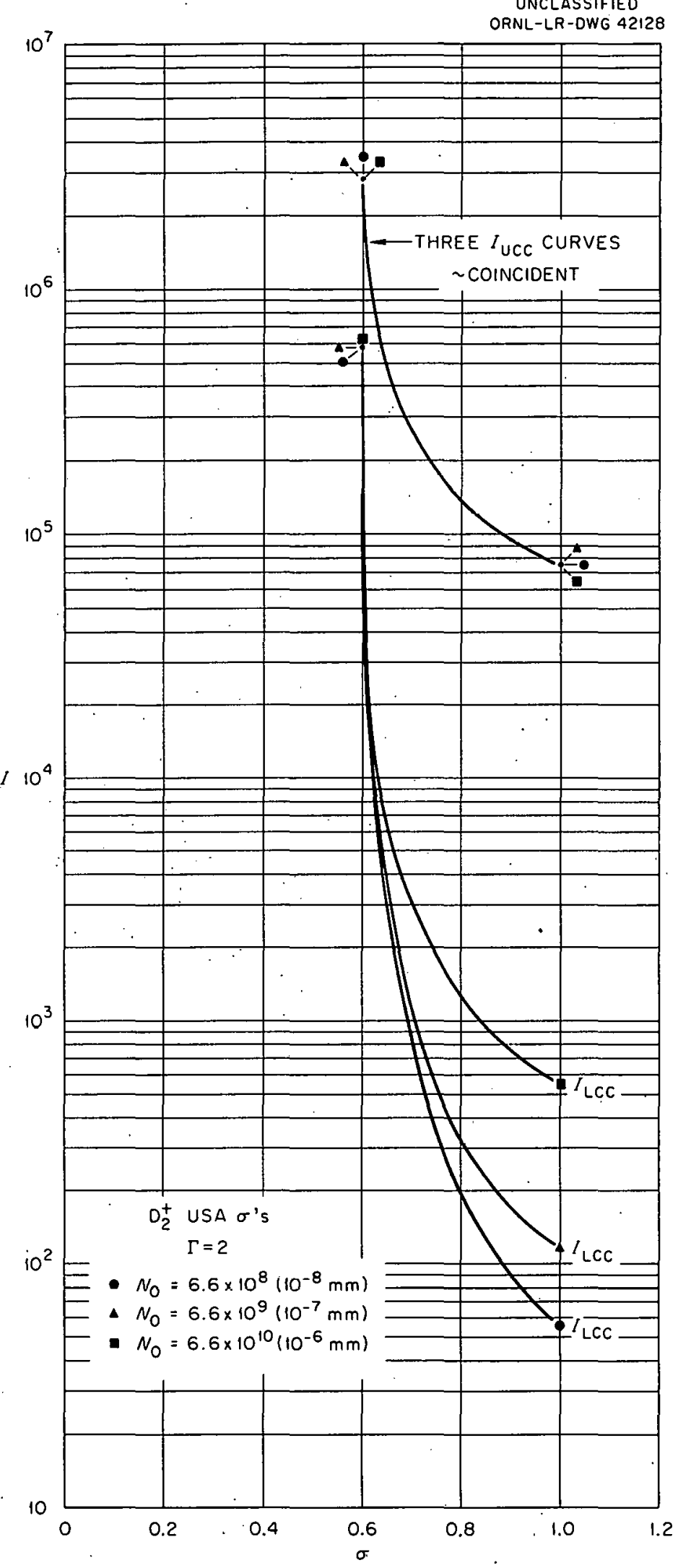

Fig. 19: 


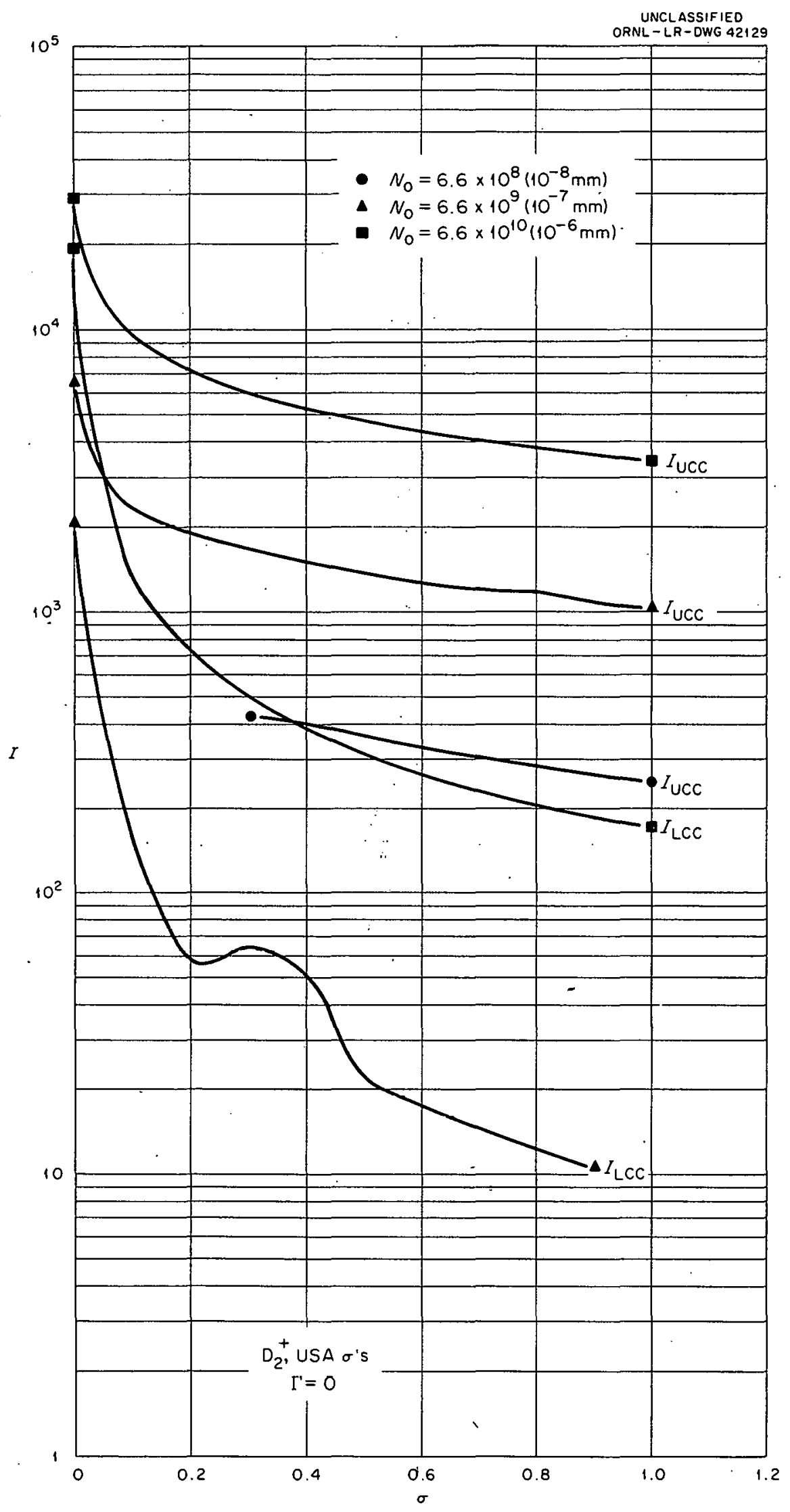

Fig. 20. 


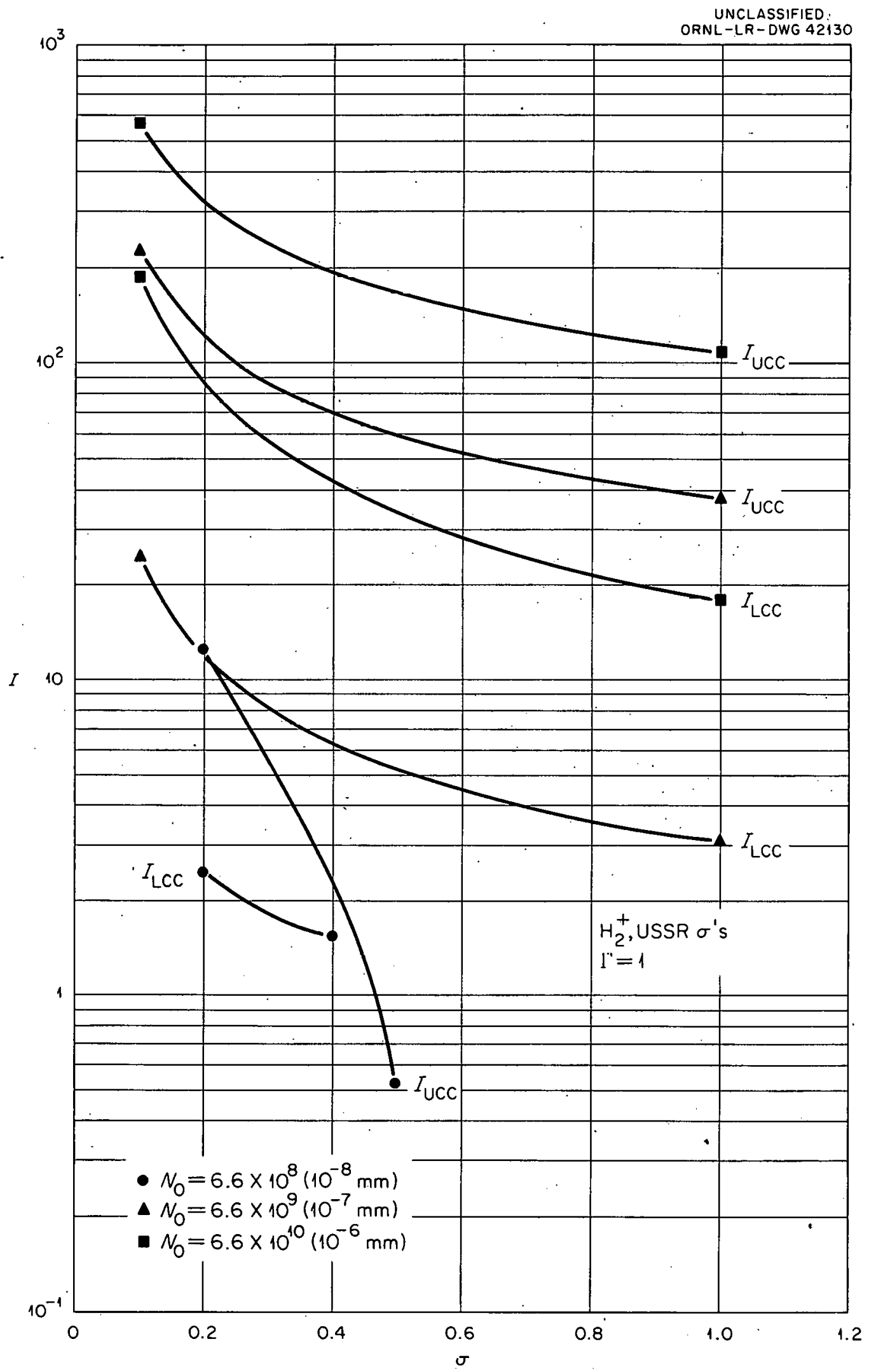

Fig. 21. 


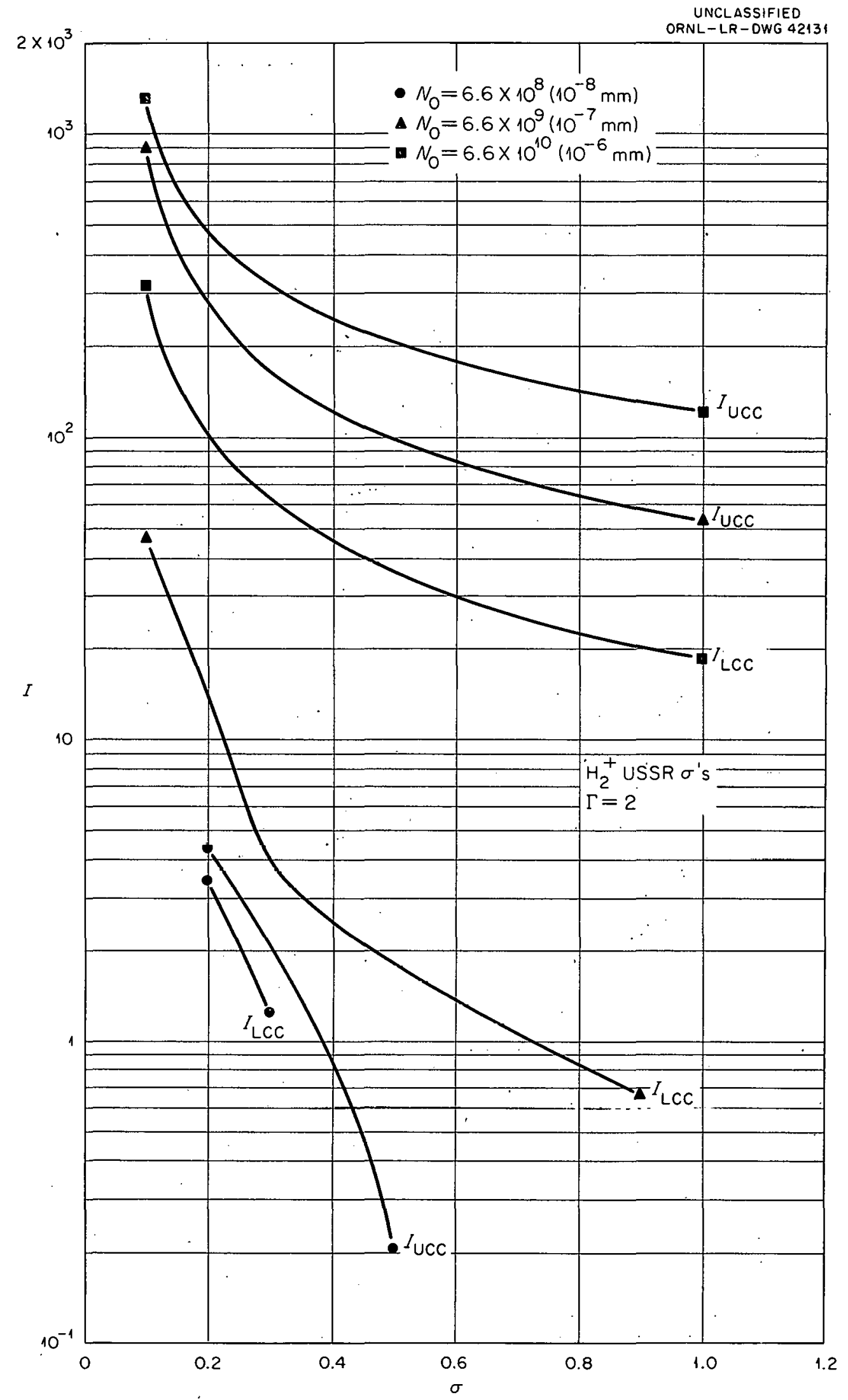

Fig. 22. 


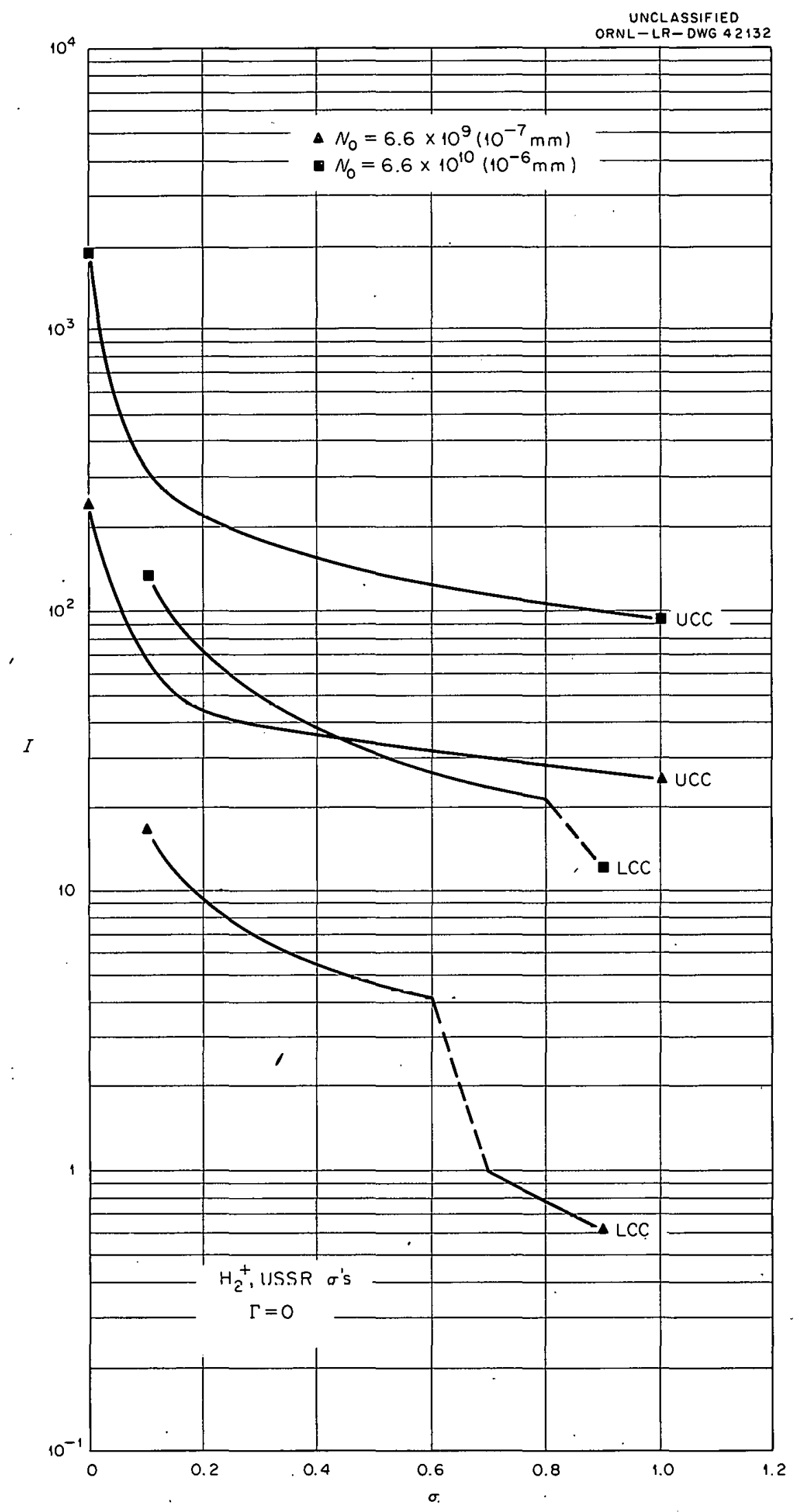

Fig. 23. 


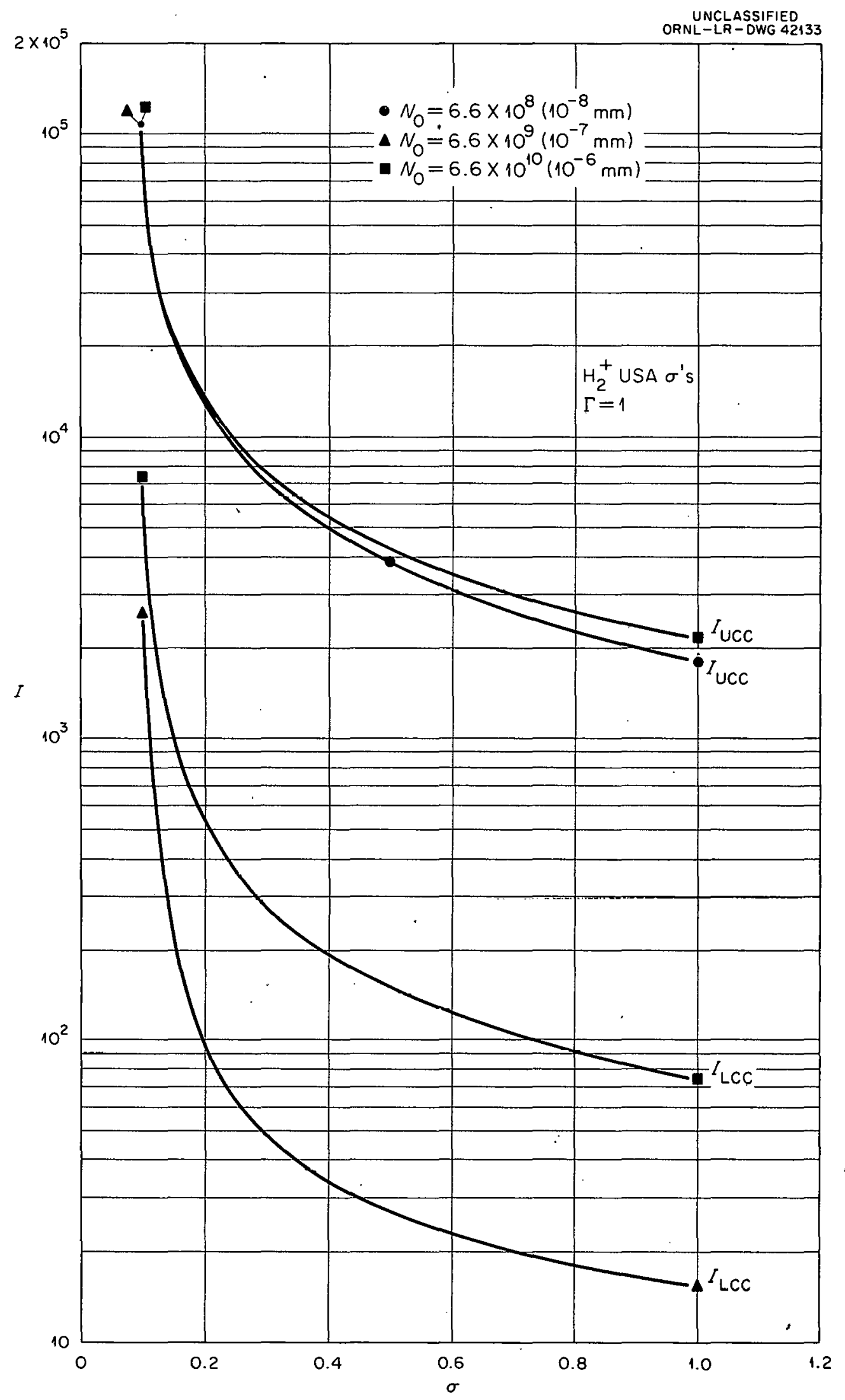

Fig. 24. 
$-41-$

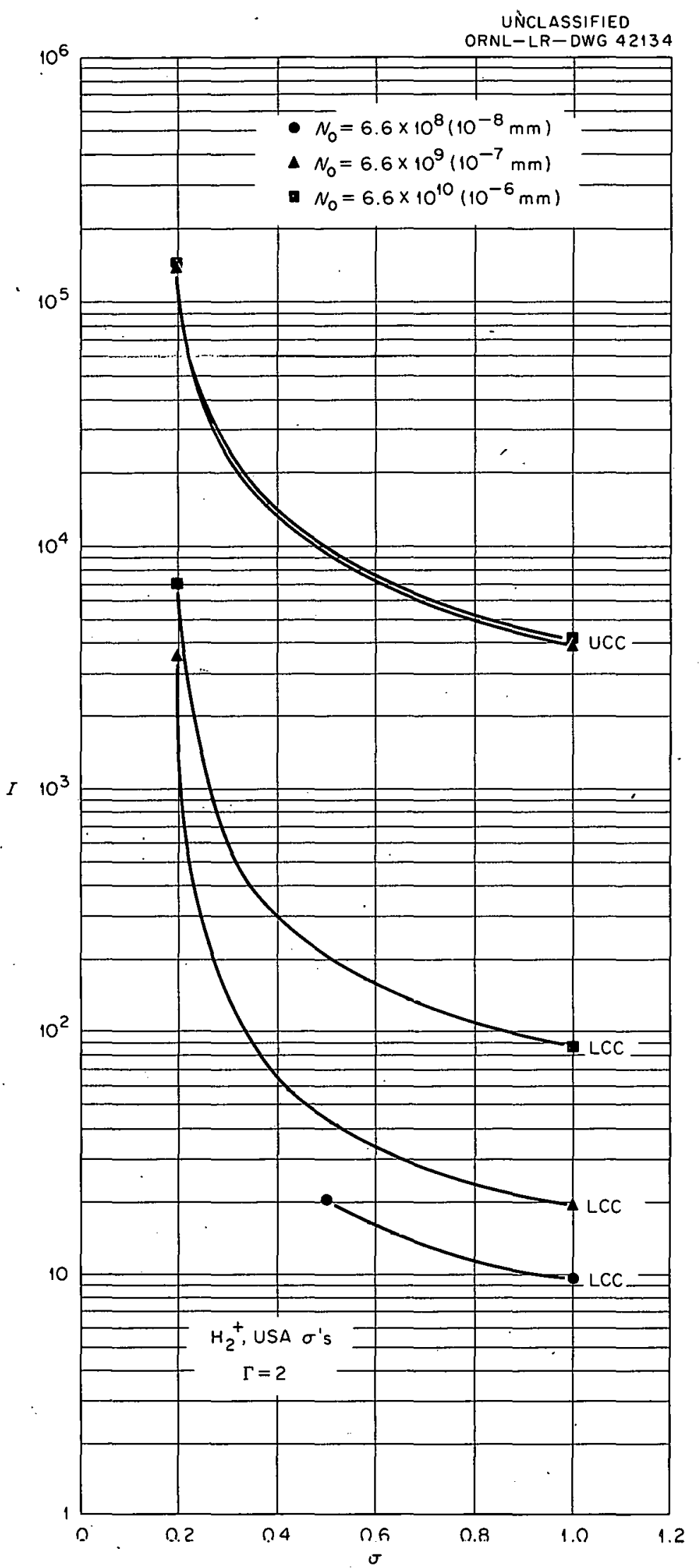

Fig. 25. 


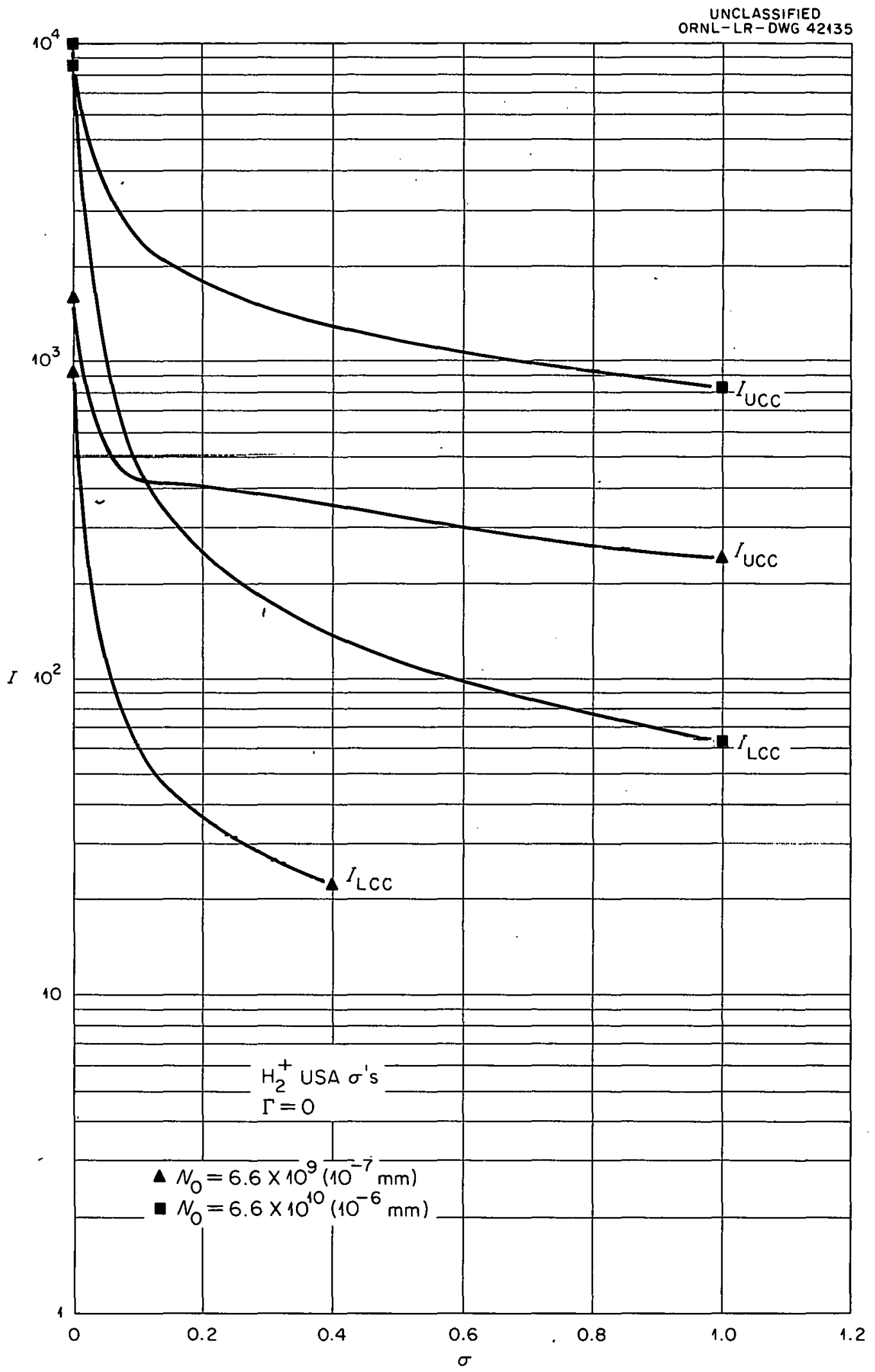

Fig. 26. 
I am greatly indebted to $M_{0} E_{0}$ Iaverne for his patient and careful handling of the numerical calculations. I am also most indebted to R. C. Gilbert and R. E. Hester for calling iny attention to the possibility of multiple roots in the gas breakup case. 
APPENDIX A

THE PATH LENGTH L CONSIDERED AS A FIXED RANGE

It is not entirely clear whether the path length I should be considered to be a mean-free-path (as it is in the text) or a fixed range. If all injected particles entered at the same spatial point with the same angle then they would all ultimately strike some obstacle after traversing a fixed path length (in the absence of transient perturbations). More realistically, the injected beam has a rather wide spread in angle. The long path length and nonuniform magnetic field then produce a great deal of orbital precession and randomization and a statistical factor (i.e., a mean free path) would seem to be more correct. Actually the calculation below indicates that the difference is not important numerically, anyway.

Let us calculate the steady-state trapping rate if there is a fixed path length I. This is obviously

$$
\left.=1-e^{-\left(\hat{N}_{0} \sigma_{B}^{0}+n_{+} \sigma_{B}+\right.}\right) L
$$

which should be compared with Eq. (4). If we define

$$
x=\left(\hat{N}_{0} \sigma_{B}^{0}+n_{+} \sigma_{\bar{B}}^{+}\right) L
$$

then the ratio of these two expressions is:

$$
R(x)=\frac{\left(1-e^{-x}\right)(1+x)}{x}
$$

This ratio approaches unity for $x$ very small and for $x$ very large compared to unity. The table below lists numerical values of $R$ for several values of $y$, where $y=e^{-x}$.

\begin{tabular}{llllllllllllll}
$\mathrm{y}\left(\equiv \mathrm{e}^{-\mathrm{x}}\right)$ & 0 & .1 & .2 & .3 & .4 & .5 & .6 & .7 & .8 & .9 & 1.0 \\
\hline $\mathrm{R}$ & 1 & 1.29 & 1.30 & 1.28 & 1.25 & 1.22 & 1.18 & 1.14 & 1.10 & 1.05 & 1 \\
\hline
\end{tabular}




\section{APPENDIX B \\ EXTENSTON OF THE DCX BURNOUT FORMULA TO \\ INCLUDE ION-PUMPING}

An approximate expression for the critical current has been derived in reference 1 and 2. We shall now derive it in a different way and then generalize to include 1on-pumping. Let us define "burnout" to be that point at which the mean-free-path of a neutral entering the plasma becomes equal to the mean chord length of the plasma volume. In the notation of this report:

$$
\lambda=\bar{\ell}
$$

or

$$
\frac{v_{0}}{v_{+} \sigma_{d}^{+}}=\bar{l}
$$

Now, since mirror loss is negligible at this point, the density is directly related to the input current by the lifetime against charge exchange. Thus

$$
\begin{aligned}
\mathrm{n}_{+} \mathrm{V} & =I \tau_{\mathrm{cx}} \\
& =\frac{I}{\overline{\mathrm{n}}_{\mathrm{o}} \sigma_{\mathrm{cx}} \mathrm{v}}
\end{aligned}
$$

Upon substitution of Eq. (B4) in Eq. (B2), we have

$$
I_{\text {crit }}=\bar{n}_{0} \frac{\sigma_{c x}}{\sigma_{d}^{+}} \frac{v_{o} v}{\bar{l}}
$$

Now 


$$
\begin{gathered}
46 \\
l=\frac{4 V}{S}
\end{gathered}
$$

and, by reference 2, Eqs. (2) and (7),

$$
\begin{aligned}
\bar{n}_{0} & =\frac{\hat{\mathrm{N}}_{0}}{1+\frac{l}{\lambda}} \\
& =\frac{\hat{N}_{0}}{2} \text { at burnout. }
\end{aligned}
$$

where $\hat{N}_{0}$ is the neutral density external to the plasma. Hence

$$
I_{\text {crit }}=\frac{\hat{N}_{0}}{2} \frac{v_{0} s}{4} \frac{\sigma_{c x}}{\sigma_{d}}
$$

This differs by a factor of 2 from the result given in reference 1. Of course, one cannot say which one is more "correct." Burnout is not a precisely defined event and either approximate expression is a useful measure of its region of onset.

The external density, $\hat{\mathrm{N}}_{o}$, is determined by the balance of wall outgassing, ion pumping, external pumping, and backstreaming from the injected beam precisely as in Section 'I of the text. Hence, by Eq. (13), we have

$$
\hat{\mathrm{N}}_{0}=\frac{\frac{\Gamma}{\theta} I+\mathrm{N}_{0}}{1+\frac{\sigma}{\theta} \frac{\mathrm{n}_{+} \sigma_{\mathrm{d}}^{+} \mathrm{vV}}{3+\frac{l}{\lambda}}}
$$

At burnout, Eqs. (BI) and (B2) apply, which gives 


$$
\hat{\mathrm{N}}_{0}=\frac{\frac{\Gamma}{\theta} \cdot I+\dot{\mathrm{N}}_{0}}{1+\frac{\sigma v_{0}}{2 \theta \bar{l}}}
$$

Upon substitution of Eq. (BII) in Eq. (B9) and rearranging, we find

$$
I_{\text {crit }}=\frac{N_{o} \frac{v_{o} s}{8} \frac{\sigma_{c x}}{\sigma_{d}^{t}}}{1+\frac{S_{0}}{8 \theta}\left(\sigma-\rho \frac{\sigma_{c x}}{\sigma_{d}^{+}}\right)} .
$$

It should be noted that burnout will be possible only if

$$
\frac{\sigma_{c x}}{\sigma_{d}^{+}} \Gamma<\sigma+2 \frac{\theta \bar{l}}{v v_{0}}
$$

which differs from Eq. (32) only by a factor of 2 in the last term. Again this difference arises from the slightly different approximations we have used. 


\section{THIS PAGE}

\section{WAS INTENTIONALLY LEFT BLANK}


ORNL-2831

Controlled Thermonuclear Processes

TID-4500 (15th ed.)

INTERNAL DISTRIBUTION

62. A. D. Callihan

63. R. R. Coveyou

64. W. Zobel

65. F. L. Keller

66. C. D. Zerby

67. D. K. Trubey

68. S. K. Penny

69. R. W. Peelle

70. F. S. Alsmiller

71. R. G. Alsmiller, Jr.

72. C. F. Barnett

73. P. R. Bell

74. E. S. Bettis

75, R. E. Clausing

76. R. A. Dandl

77. L. Dresner

78. T. K. Fowler

79. W. F. Gauster

80. G. G. Kelley

81. R. J. Kerr

82. N. H. Lazar

83. J. S. Luce

84. R. J. Mackin, Jr.

85. J. R. McNally, Jr.

86. C. D. Moak

87. R. V. Neidigh

88. J. H. Neiler

89: C. E. Normand

90. M. Rankin

91. C. H. Weaver

92. T. A. Welton

93. A. Zuker

94. E. G. Harris

95-99. A. Simon

100. P. M. Reyling

101. F. L. Friedman (consultant)

102. H. Goldstein (consultant)

103. H. Hurwitz, Jr. (consultant)

104. L. W. Nordheim (consultant)

105. R. F. Taschek (consultant)

106. ORNL-Y-12 Technical Library, Document Reference Section 


\section{EXTERRITAL DISTRIBUTITON}

107. Division of Research and Development, AEC, ORO

108-70i. Given distribution. as shown in TID 4500 (15th ed.) under Controlled Thermonuclear Processes Category (75 copies - OIS) 